NBER WORKING PAPER SERIES

\title{
TECHNOLOGY AND PRODUCTION FRAGMENTATION: DOMESTIC VERSUS FOREIGN SOURCING
}

\author{
Teresa C. Fort \\ Working Paper 22550 \\ http://www.nber.org/papers/w22550 \\ NATIONAL BUREAU OF ECONOMIC RESEARCH \\ 1050 Massachusetts Avenue \\ Cambridge, MA 02138 \\ August 2016
}

Previous versions of this paper were entitled "Breaking up is hard to do: Why firms fragment production across locations." I am very grateful to John Haltiwanger and Nuno Limão for their advice, support and encouragement. I thank Pol Antràs, Emek Basker, Andy Bernard, Emily Blanchard, Rafael Dix-Carneiro, Brad Jensen, Rob Johnson, Kyle Handley, Jonathan Haskel, Brad Jensen, Rafael La Porta, Andreas Moxnes, Nina Pavcnik, John Shea, Matt Slaughter, Doug Staiger, Felix Tintelnot, the Editor, and three anonymous referees for valuable input. I also thank numerous conference and seminar participants for helpful comments and suggestions. I thank Jim Davis for help with the disclosure process. Any opinions and conclusions expressed herein are those of the author and do not necessarily represent the views of the U.S. Census Bureau or the National Bureau of Economic Research. All results have been reviewed to ensure that no confidential information is disclosed.

NBER working papers are circulated for discussion and comment purposes. They have not been peer-reviewed or been subject to the review by the NBER Board of Directors that accompanies official NBER publications.

(C) 2016 by Teresa C. Fort. All rights reserved. Short sections of text, not to exceed two paragraphs, may be quoted without explicit permission provided that full credit, including () notice, is given to the source. 
Technology and Production Fragmentation: Domestic versus Foreign Sourcing

Teresa C. Fort

NBER Working Paper No. 22550

August 2016, Revised October 2016

JEL No. F14,F23,L23

\begin{abstract}
$\underline{\text { ABSTRACT }}$
This paper provides direct empirical evidence on the relationship between technology and firms' global sourcing strategies. Using new data on U.S. firms' decisions to contract for manufacturing services from domestic or foreign suppliers, I show that a firm's adoption of communication technology between 2002 to 2007 is associated with a 3.1 point increase in its probability of fragmentation. The effect of firm technology also differs significantly across industries; in 2007, it is 20 percent higher, relative to the mean, in industries with production specifications that are easier to codify in an electronic format. These patterns suggest that technology lowers coordination costs, though its effect is disproportionately higher for domestic rather than foreign sourcing. The larger impact on domestic fragmentation highlights its importance as an alternative to offshoring, and can be explained by complementarities between technology and worker skill. High technology firms and industries are more likely to source from high human capital countries, and the differential impact of technology across industries is strongly increasing in country human capital.
\end{abstract}

Teresa C. Fort

Tuck School of Business

Dartmouth College

100 Tuck Hall

Hanover, NH 03755

and NBER

teresa.fort@tuck.dartmouth.edu

A data appendix is available at http://www.nber.org/data-appendix/w22550

A Data is available at http://faculty.tuck.dartmouth.edu/teresa-fort/data/ 


\section{Introduction}

Changes in communication and information technology have revolutionized how people and businesses interact around the world. It is now easier than ever to disseminate information, collaborate across distances, and coordinate activities. These changes in technology have been accompanied by large increases in global production sharing as firms increasingly break apart, or fragment, their production process across different countries (Campa and Goldberg, 1997; Hummels et al., 2001; Johnson and Noguera, 2012). Because this type of fragmentation, or "offshoring" requires relaying design and production specifications to suppliers, it is not surprising that the increase in offshoring is often attributed to concurrent advances in communication technology. In fact, technological improvements play a central role in a number of theoretical models on offshoring (Jones and Kierzkowski, 2001; Deardorff, 2001; Kohler, 2004; Antràs et al., 2008; Grossman and Rossi-Hansberg, 2008; Costinot et al., 2013).

Despite the importance that technology may play in shaping global production patterns, and the fact that the welfare predictions in the models listed above crucially depend upon how technology affects offshoring, there is little or no empirical evidence on the relationship. ${ }^{1}$ The lack of evidence is driven by a lack of data. Production fragmentation and technology are both difficult to measure. In addition, technology adoption is clearly endogenous, making identification of its effect on fragmentation particularly difficult with aggregate data.

In this paper, I provide direct evidence on the relationship between a firm's use of technology and its decisions to fragment production across distinct geographic locations that are both foreign and domestic. To do so, I construct a unique new dataset on plant-level fragmentation decisions from the 2007 Census of Manufactures. The data identify whether a plant purchased contract manufacturing services from other plants (within its company or from another company); and if so, whether the plant purchased these services primarily domestically or abroad. Contract manufacturing services (CMS) entail an arrangement in which the fragmenting plant provides design and production criteria to a manufacturer who performs the physical transformation activities, generally on materials or

\footnotetext{
${ }^{1}$ For example, an important assumption in Grossman and Rossi-Hansberg (2008) is that technology affects offshoring costs for all tasks in the same way. This delivers a "productivity effect" in which firms' production savings on all previously offshored tasks increase when technology improves. The productivity effect would be absent if technological improvements did not generate additional savings for the set of tasks already being offshored.
} 
inputs specified by the purchaser. Although CMS purchases only include customized fragmentation (off-the-shelf inputs are not included), the fact that they require communicating production specifications across locations makes them uniquely suited to assess the role of communication technology in fragmentation. These data also constitute a significant improvement over many existing measures of offshoring. They are a plant-level variable that clearly identifies fragmentation and allows for a direct comparison of domestic versus foreign sourcing.

The CMS data yield three new facts on fragmentation. First, a significant fraction of plants and firms do not fragment their production of customized inputs, even within industries. The average four-digit NAICS industry has about 30 percent of plants purchasing CMS, while the lowest industry participation rate is 8 percent and the highest is over 60 percent. Second, domestic fragmentation is far more prevalent than offshoring. In the aggregate, 27 percent of plants primarily purchase domestic CMS while only two percent purchase CMS primarily offshore. Finally, plants that purchase CMS are larger and more productive than non-purchasers, particularly if they offshore. Plants that purchase CMS domestically have sales that are 28 percent larger than the average plant in the their industry, and offshorers are more than twice the size of the average establishment.

I exploit the variation in fragmentation status within and across industries to estimate the relationship between a plant's decision to fragment production and its communication technology. Plant-level communication technology is an indicator equal to one if the plant has integrated electronic communication with its production process. The data show a strong, positive relationship between plant technology and fragmentation, both in the cross-section and when using panel data to control for plant fixed effects. ${ }^{2}$ The estimates from the panel analysis suggest that a firm's adoption of communication technology between 2002 to 2007 is associated with a 3.1 percentage point increase in its probability of fragmentation over the period. This positive relationship could reflect technology's ability to lower fragmentation costs (e.g., Grossman and Rossi-Hansberg, 2008). An alternative explanation is that a shock to fragmentation costs may have induced firms to adopt new technology as a way to exploit the new trade opportunities (e.g., Lileeva and Trefler, 2010).

In light of these challenges, I focus on technology's potential role in facilitating communication

\footnotetext{
${ }^{2}$ The panel data are available only for the subset of single-unit firms and do not distinguish between domestic and foreign sourcing.
} 
about production specifications across locations. If this mechanism is at work, technology's impact will depend upon a firm's ability to codify its product specifications in an electronic format. Computeraided design $(\mathrm{CAD})$ and computer-aided manufacturing (CAM) software are the predominant tools used to transmit manufacturing designs and specifications electronically. I therefore measure electronic codifiability as the fraction of plants in an industry that used CAD/CAM software in their production process in $1999 .^{3}$ I interact a plant's communication technology with its industry CAD intensity. This estimation technique is comparable to a difference-in-difference estimator in which CAD intensity is a continuous treatment variable. Identification is based on the differential impact of electronic communication as a function of CAD intensity, rather than on its level effect. This strategy is similar to the one employed by Rajan and Zingales (1998) and Nunn (2007) who interact country and industry variables for identification. My approach differs by exploiting industry and plant-level information on technology to identify a specific channel through which it may affect plants' domestic or foreign sourcing.

The estimates reveal a systematic differential impact of communication technology across industries. While plant use of networks increases the probability of fragmentation in all industries, its effect is about six percentage points larger in the highest CAD intensity industry (semiconductor machinery manufacturing) compared to one of the lowest intensity industries (other apparel manufacturing). This differential impact is statistically and economically significant; it is about 20 percent of the mean share of fragmenting establishments. I also estimate the probability that a fragmenting plant will source primarily from foreign locations. ${ }^{4}$ If coordination costs are increasing in distance, then we would expect a differential impact of electronic communication to be evident in fragmenting plants' decision to offshore. Surprisingly, however, the data suggest the opposite. The probability that a fragmenting

\footnotetext{
${ }^{3}$ Multiple conversations with suppliers at CMS trade shows indicated that the ability to communicate electronically has lowered fragmentation costs more in industries in which production specifications are readily codified in an electronic format. For example, a gasket producer described costs that fell from "hundreds of dollars to cents" when CAD files that could be plugged into CAM programs replaced conventional drawings, sent via fax, that required additional verbal communication to interpret. In contrast, a spring manufacturer whose production process does not work with CAM software did not experience these cost reductions from electronic communication. These conversations took place at Mid-Atlantic Design-2 Part Shows in April 2011 and November 2010.

${ }^{4}$ This conditional regression, which is based only on the subset of plants that fragment production, avoids confounding factors that affect plants' decisions to break apart their production process with factors that affect their choice to offshore. In the appendix, I show that the results are robust to: a) a nested logit specification in which the top tree is the decision to fragment and the bottom tree is the decision to offshore; and b) an IV approach in which I condition on plants that did not fragment production in 2002 and instrument for 2007 technology using technology in 2002.
} 
plant using electronic networks will offshore is decreasing in its industry CAD intensity, suggesting that electronic communication lowers coordination costs disproportionately more for domestic rather than foreign sourcing.

Why would communication technology have a disproportionately larger effect on domestic fragmentation? Existing work on technology and firm organization documents important complementarities between worker skill and technology (e.g., Crespi et al., 2007; Bresnahan et al., 2002). Firms that use technology to lower fragmentation costs may therefore also require high-skilled suppliers. By linking the CMS data to the U.S. Customs Import Transaction Database, I assess this explanation using a triple interaction between firm communication technology, industry CAD intensity, and country human capital. This approach is similar to a triple difference estimator, and shows that the differential impact of networks by industry CAD is strongly increasing in country human capital. These results are consistent with the premise that firm communication technology facilitates fragmentation for offshoring to high human capital countries, but not for sourcing from low skill countries. ${ }^{5}$

The empirical analyses also assess the role of productivity, labor cost differences, and distance to potential suppliers in firms' fragmentation strategies. In line with heterogeneous firm models, the probabilities of fragmentation and offshoring are both increasing in plant-level productivity. The data are also consistent with labor cost savings being a motive for fragmentation, with plants in high-wage locations being more likely to purchase CMS. Finally, the results extend existing evidence on the importance of domestic distances in trade costs (Hillberry and Hummels, 2008; Holmes and Stevens, 2012). Both the plant-level fragmentation regressions and the firm-country level regressions show that heterogeneity in firms' distances to potential domestic and foreign suppliers affect their sourcing decisions.

An important contribution of the paper is to consider the option of domestic fragmentation in firms' foreign sourcing decisions. There has been considerable work on offshoring, but domestic sourcing is not usually considered as an alternative. A notable exception is Kee and Tang (2016), who document significant firm-level heterogeneity in the aggregate rise of the domestic value-added content of Chinese processing firms. While those authors focus on the role of foreign direct investment and input tariffs in

\footnotetext{
${ }^{5}$ In section 5, I show that offshoring firms source a significant fraction of imports from low-income countries, where average worker skill tends to be lower than average domestic skill.
} 
explaining domestic value-added, this paper assesses how technology affects both domestic and foreign sourcing decisions. ${ }^{6}$ Although the results do support the premise that technology lowers coordination costs across locations, it seems to do so relatively more for domestic, rather than foreign sourcing.

The paper also contributes to a growing body of empirical work on the relationship between foreign trade and technology. A number of papers analyze how trade affects firms' adoption of technology (Melitz and Constantini, 2008; Lileeva and Trefler, 2010; Bustos, 2011; Boler et al., 2015; Bloom et al., 2016). I do not model the decision to adopt technology, but instead employ a difference-in-difference approach to assess the relationship between communication technology and firms' decisions to fragment production and offshore. Feinberg and Keane (2006) find that technology, measured as the residual from a structural model, is an important factor in intra-firm trade by multinationals between the U.S. and Canada. The analysis here uses a direct plant-level measure of communication technology, and provides evidence on how it lowers the coordination costs associated with fragmentation. While this channel is intuitive, I show that the effect of technology varies systematically across industries, and is more important for offshoring to high, rather than low, human capital countries. ${ }^{7}$

Finally, the paper extends the literature on technology and the organization of the firm. Existing work finds that technology may change optimal organizational practices within the firm (Brynjofsson and Hitt, 2000), optimal firm boundaries (Baker and Hubbard, 2003, 2004; Acemoglu et al., 2010), and the decentralization of control within a firm (Acemoglu et al., 2007; Bloom et al., 2011). I analyze the decision to break apart the production process itself, which is often a prerequisite of outsourcing or decentralization. This margin has received little attention in the literature, despite the fact that ignoring first stage extensive margin decisions can lead to biased estimates of aggregate effects (e.g. Helpman et al., 2008). The positive and significant interaction between firm technology and country human capital is also consistent with complementarities between technology and skill documented in Bresnahan et al. (2002), and with models that feature positive assortative matching in teams that form across locations (Antràs et al., 2006, 2008; Grossman et al., forth; Sampson, 2014). Firms that leverage

\footnotetext{
${ }^{6}$ Fally (2012) uses input-output tables to measure domestic fragmentation over time, but the aggregate data tell us little about individual firm decisions. Akerman and Py (2011) analyze how market size affects the trade-off between the gains to specialization and contracting frictions for firms' domestic outsourcing decisions.

${ }^{7}$ In this regard, the paper builds on evidence about the importance of comparative advantage- documented at the industry product levels by Yeaple (2003) and Schott (2004) respectively- by showing how firm-level technology can interact with country characteristics to shape trade patterns.
} 
technology to reduce fragmentation costs may not only hire higher skilled workers themselves, but also require higher skilled suppliers. As a result, production fragmentation may be an additional channel through which skill-biased technical change affects the relative demand for skilled versus unskilled labor in both developed and developing countries.

The rest of the paper proceeds as follows. Section 2 describes the CMS data, presents three new facts about customized fragmentation, and provides descriptive evidence on technology and fragmentation. In Section 3, I discuss theoretical channels through which technology and fragmentation may be related and describe the identification strategy. In section 4, I present estimates on the role of communication technology and fragmentation, and in section 5 I show how this relationship depends upon country human capital. The last section concludes.

\section{Data description and stylized facts}

In this section, I describe the new CMS data and explain the type of sourcing activities they cover. I then provide three novel facts about domestic and foreign fragmentation, as well as new evidence on the relationship between communication technology and fragmentation.

\subsection{Data sources}

The primary data used in this paper are compiled from three different sources. The fragmentation and technology data are from the 2007 U.S. Census of Manufactures (CM), which is conducted in years that end in 2 and 7. The CM covers the universe of manufacturing establishments, though the fragmentation data are based on a new question that is available for a subset of plants that covers 75 percent of manufacturing sales. Details of the sample and corrections for possible sample selection are in the data appendix.

The new fragmentation question asked, "Did this establishment purchase contract manufacturing services from other companies or other establishments of your company to process materials or components that this establishment owns or controls?" Establishments that answer yes are also asked whether they primarily purchase these services domestically or abroad. ${ }^{8}$ Contract manufacturing

\footnotetext{
${ }^{8}$ The term "primarily" refers to the value of CMS purchases made by the establishment. An establishment denotes a single physical location where business transactions take place and for which payroll and employment records are kept.
} 
services (CMS) is a term used by practitioners that covers input production or assembly that is customized by the supplier to meet specifications provided by the fragmenting plant. The CM also provides information on plants' manufacturing sales, value-added, employees, and industry.

I match the CM data to the Business Register to identify plants' latitude and longitude. Using a firm identifier, I also aggregate the data to the firm level. While the fragmentation question design means that a single plant can only source primarily domestically or primarily offshore, multi-unit firms can potentially do both. Firms with at least one plant that purchases domestic CMS and at least one plant that purchases foreign CMS are therefore classified as "Domestic and Offshore Purchases." Finally, I link the firm-level data to U.S. Customs import transactions to identify the values and source countries of firms' imports. ${ }^{9}$

In the descriptive evidence that follows, I relate fragmentation to a number of four-digit North American Industrial Classification System (NAICS) industry and country characteristics. I measure the extent to which an industry-level production process can be codified electronically as the share of manufacturing plants in an industry that report using Computer-aided design (CAD) and computeraided manufacturing (CAM) software in the 1999 Computer Survey Network Use Supplement (CNUS) of the Annual Survey of Manufactures (ASM). I also measure the industry share of differentiated inputs from Nunn (2007), skill and capital intensity from the NBER productivity database, and routineness from Costinot et al. (2011). ${ }^{10}$ Country human capital is defined as in Hall and Jones (1999), but based on updated 2005 education data from Barro and Lee (2000).

\subsection{Description of contract manufacturing services}

It is important to be clear about what the CMS data do and do not cover. First, note that the question explicitly asks about CMS purchases from other companies (i.e., outsourcing) as well as purchases from other units within the same company. The data are therefore not limited to outsourcing, but also include transactions within the boundary of the firm. The term "fragmentation of production"

\footnotetext{
The question as it appeared on the Census form is presented in the data appendix.

${ }^{9}$ The trade data are available by employer identification number (EIN), so is not possible to link the trade transactions data to individual establishments for multi-unit firms. I use a firm identifier to aggregate EINs to the firm level.

${ }^{10}$ Skill intensity is the share of non-production workers to total workers. Capital intensity is the ratio of capital expenditures to employees. Routineness is measured as 1 - (importance of thinking creatively). I thank Lindsay Oldenski for sharing this measure.
} 
is useful since it describes the separation of production into parts that are performed in distinct geographic locations, either domestically or offshore, as well as within or outside the firm. ${ }^{11}$

Second, the CMS data cover fragmentation of customized inputs for which the fragmenting establishment provides design and production criteria to its supplier. The analysis in this paper therefore covers customized fragmentation of production, but does not include fragmentation of standardized, off-the-shelf inputs. Since the former necessarily requires communicating specifications across locations, the data are uniquely suited to assess the role of communication technology in fragmentation. This feature of the data also constitutes a significant improvement on many prior measures of offshoring. Existing work tends to rely on imported intermediates as a measure of foreign fragmentation. However, intermediate trade measures are often based on input-output tables that are relatively coarse and therefore unlikely to identify intermediate inputs exclusively or entirely. In addition, imported intermediates are not a complete offshoring measure since they exclude any final goods that are assembled overseas, while they may include imports of commodities or standardized inputs that are not part of a manufacturer's production process. The CMS data contain none of this ambiguity and clearly reflect offshoring activity. To the extent that fragmentation of non-customized processes does not require coordinating production across locations, the estimated effects of technology on fragmentation based on these data likely represent an upper bound.

Third, the CMS data distinguish between domestic and foreign sourcing for the same type of fragmentation. Specifically, the data include the possibility that plants do not purchase customized inputs, which implies that the plant does not use customized inputs or produces them all on site. This feature is important since it allows for a direct comparison between domestic and foreign sourcing that is not contaminated by firms' decisions about whether to break apart the production process itself. ${ }^{12}$

\footnotetext{
${ }^{11}$ The fact that two establishments are in the same firm does not preclude them from contracting with each other. If firm boundaries were substitutes for contractual relationships, then the classic hold-up problem would be solved by integration. However, principal agent problems exist within the boundary of the firm and optimal organization structures are designed to address differences in individuals' incentives that cannot be aligned due to contractual incompleteness (e.g., as in Grossman and Hart, 1986) . A limitation of the data is that they do not distinguish between fragmentation that takes place within or outside the firm so that it is not possible to investigate optimal firm boundaries.

${ }^{12} \mathrm{~A}$ potential issue is that the data do not provide the value of CMS purchases, and instead only ask whether purchases were made primarily domestically or primarily offshore. I use the linked import data to assess this concern. While the average firm with primarily domestic CMS purchases has total imports equal to just three percent of its sales, firms that primarily offshore import an average of 20 percent of their sales. Since the import data are collected through an entirely different venue (via Customs form declarations), this is reassuring evidence that the CMS data provide an accurate depiction of firms' sourcing strategies.
} 


\subsection{Description of communication technology}

The 2007 CM also has a direct measure of plants' use of electronic networks to control or coordinate their shipments. Electronic networks include the internet, electronic data interchange (EDI), e-mail, extranet, or other online systems. While this is the only technology variable available in 2007 , there is a rich set of information on plants' use of different technologies in the 1999 CNUS of the ASM. The CNUS data show that a plant's use of electronic networks to control or coordinate its shipments is a good proxy measure for whether it has integrated electronic communication into its production process. First, a plant's use of networks to coordinate shipments involves more than just being online. Approximately 87 percent of manufacturing plants in the 1999 ASM used an electronic network at their plant, while only 31 percent and 33 percent of the ASM plants accepted or placed orders online respectively. Second, over half of the manufacturing plants that used networks to coordinate shipments in 1999 also used networks to make input purchases. Third, plants using networks to coordinate shipments are twice as likely to provide information about their design specifications to external suppliers.

I use the information on whether a plant used electronic networks to coordinate shipments, which is available for all plants in the CMS sample, to construct an indicator equal to one for plant use of communication technology. It is important to stress that this is not just a measure of whether the plant had access to the internet. As described above, it is a suitable proxy for whether a plant has integrated electronic communication into its production process.

\subsection{Stylized facts about customized fragmentation}

The most striking feature of the CMS data is that most plants do not fragment customized production processes. Table 1 presents shares of plants, sales, and employment by CMS purchase status. The first column shows that 27 percent of plants fragment primarily domestically, and only two percent fragment primarily offshore. ${ }^{13}$ While the shares of sales and employment, reported in columns 2

\footnotetext{
${ }^{13}$ This finding is similar to evidence in Tomiura (2007) who finds that only five percent of Japanese manufacturing firms offshore production. There is limited evidence on plants' domestic fragmentation. Fally (2012) uses aggregate inputoutput tables to calculate the average number of sequential stages of domestic production and finds low fragmentation rates in the U.S., while Kohler and Smolka (2011) document that 90 percent of Spanish manufactures with 10+ employees outsource domestically. The results here point to much lower rates of fragmentation of customized manufacturing inputs, even on sales or employment-weighted basis.
} 
and 3 are much higher, they still show that the majority of economic activity is in non-fragmenting establishments. Plants that purchase CMS domestically employ 35 percent of workers and sell 39 percent of total sales. Offshoring plants account for four percent of employment and sales.

Table 1: Participation shares by contract manufacturing services purchase status

\begin{tabular}{lcccccccc}
\hline & \multicolumn{3}{c}{ Plant Shares } & & \multicolumn{3}{c}{ Firm Shares } \\
\cline { 2 - 3 } \cline { 8 - 9 } & Plants & Sales & Emp & & Firms & Sales & Emp \\
\cline { 2 - 4 } No Purchases & 0.71 & 0.57 & 0.61 & & 0.69 & 0.29 & 0.39 \\
Domestic Purchases & 0.27 & 0.39 & 0.35 & & 0.28 & 0.46 & 0.41 \\
Offshore Purchases & 0.02 & 0.04 & 0.04 & & 0.02 & 0.02 & 0.03 \\
Domestic \& Offshore & na & na & na & & $<0.01$ & 0.23 & 0.17 \\
\hline
\end{tabular}

Notes: Sales and employment shares weighted by the inverse probability of inclusion in the CMS sample.

The right panel of Table 1 presents CMS participation shares at the firm level. First note that, as at the plant level, the majority of firms do not purchase CMS. Only two percent of firms source offshore, while 28 percent fragment domestically. In contrast, firms that purchase CMS account for 71 percent of manufacturing sales and 61 percent of employment. These activity-weighted firm participation shares show that firms engaged in production fragmentation matter in the aggregate.

The low fraction of plants purchasing CMS may be due to compositional differences in fragmentation strategies across industries. To assess how fragmentation varies across industries, I calculate the fraction of plants that purchases CMS in each of the 86 four-digit NAICS manufacturing industries. The average share of fragmenting plants per industry is 0.29 with a standard deviation of 0.12 . In addition, a large portion of plants does not purchase CMS in every industry. These findings lead to:

Fact 1: A significant fraction of plants does not fragment its production process for customized inputs within every industry.

Figure 1a shows how the share of plants that purchase CMS in an industry relates to the share that use electronic communication to control or coordinate shipments. The figure depicts a strong positive correlation between industry fragmentation and technology shares. Motor vehicle manufacturing (3361) stands out as one of the industries with highest fraction of plants using communication technology and fragmenting production, while cement and concrete product manufacturing has low shares of both. Table A.2 in the online appendix also shows that the industry share of plants pur- 
chasing CMS is increasing in CAD intensity (CAD/CAM are the predominant tools used to translate manufacturing designs and specifications into an electronic format), the share of differentiated inputs, and skill intensity. In contrast, there is no relationship with industry capital intensity and a negative relationship with routineness. These results are consistent with the fact that CMS purchases entail customization by suppliers. The same basic patterns hold for offshoring shares, though the correlations are smaller. Among plants that purchase CMS, the share that source primarily offshore tends to be higher in more skill intensive industries and in industries with a higher fraction of differentiated inputs.

Figure 1: Fragmentation and offshoring across industries and countries

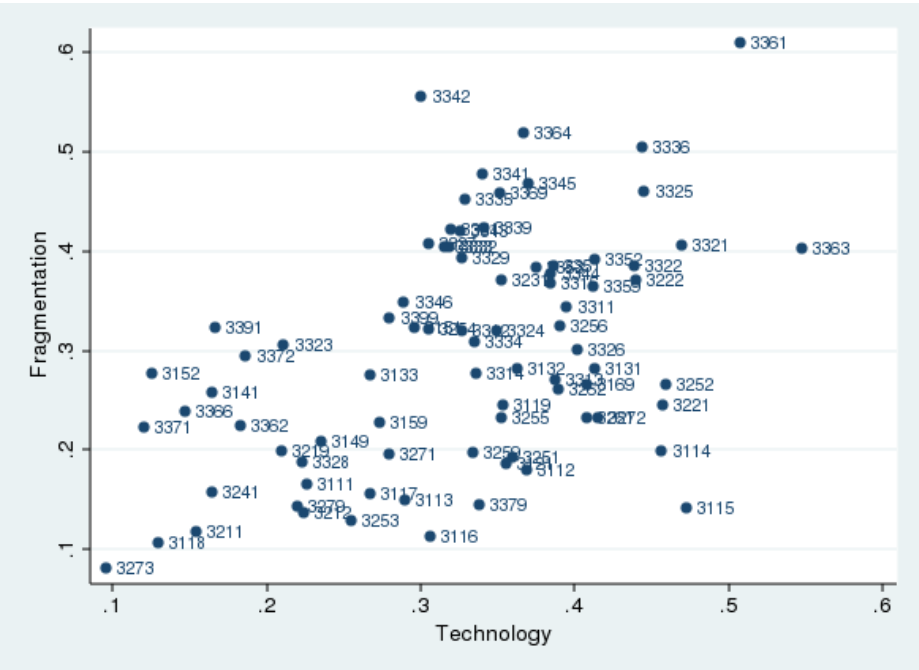

(a) Industry fragmentation versus communication technology

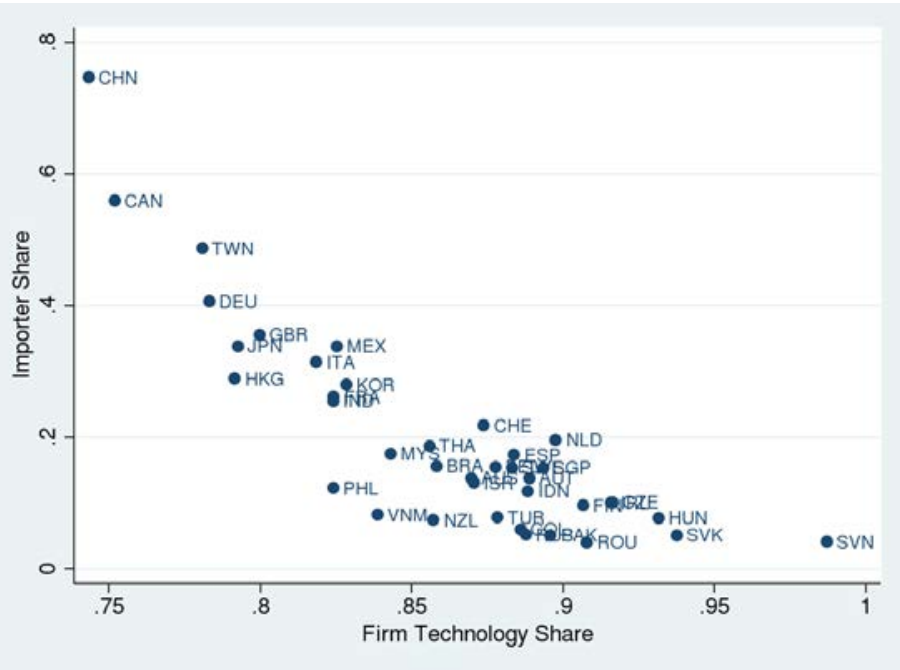

(b) Offshoring versus communication technology

Notes: Panel (a) plots industry shares of fragmentation against shares of plants that use electronic communication to control or coordinate shipments. 5 industries suppressed for disclosure avoidance. Panel (b) plots share of offshoring firms that source from a country against the share of those firms that use electronic communication to control or coordinate shipments. Figure includes only those countries with 75 or more offshoring firms that source from them. Nine countries suppressed for disclosure avoidance.

I also assess the prevalence of domestic versus foreign CMS purchases within industries. Table 2 presents the industry distribution of the share of plants that purchase CMS domestically and offshore. The first column shows that there are two industries in which no plants offshore production. In one of these non-offshoring industries, 10-20 percent of the plants purchase CMS domestically, while in the other industry 20-35 percent of plants do. In fact, all industries have a positive share of plants that purchase domestic CMS- at least five percent of the plants in every industry fragment domestically. 
Examining the diagonal of Table 2, it is also evident that every industry has more plants that purchase CMS domestically rather than offshore. This evidence is summarized by:

Fact 2: Domestic fragmentation is more prevalent than offshoring among plants within every industry.

Table 2: Industry distribution of the share of establishments that purchase CMS

\begin{tabular}{|c|c|c|c|c|c|}
\hline \multirow{2}{*}{$\begin{array}{l}\text { Domestic Purchases } \\
\text { (\% of estabs in industry) }\end{array}$} & \multicolumn{5}{|c|}{$\begin{array}{l}\text { Offshore Purchases } \\
\text { (\% of estabs in industry) }\end{array}$} \\
\hline & $0 \%$ & $0-5 \%$ & $5-10 \%$ & $10-20 \%$ & Total \\
\hline $5-10 \%$ & 0 & 2 & 0 & 0 & 2 \\
\hline $10-20 \%$ & 1 & 22 & 2 & 0 & 25 \\
\hline $20-35 \%$ & 1 & 31 & 6 & 2 & 40 \\
\hline $35-50 \%$ & 0 & 13 & 4 & 1 & 18 \\
\hline $50-60 \%$ & 0 & 1 & 0 & 0 & 1 \\
\hline Total & 2 & 69 & 12 & 3 & 86 \\
\hline
\end{tabular}

The evidence presented thus far depicts considerable heterogeneity within industries in plants' fragmentation and offshoring decisions. Table 3 documents how this variation is systematically related to plant size and productivity. Columns 1 and 2 indicate that the average fragmenting plant is larger and more productive than the average non-fragmenter. In addition, plants that fragment production offshore are larger and more productive than domestic fragmenters. To assess whether these patterns are due to compositional differences across industries, I calculate a relative measure $x_{i, g} / \bar{x}_{g}$, where $\bar{x}_{g}$ is the mean of variable $x$ for the six-digit NAICS industry $g$. Columns 4-6 show that the same orderings hold within industries. Figure 2 depicts these patterns for firm sales, clearly showing that domestic fragmenters are larger than non-fragmenters, and offshorers are the largest firms. Plants that purchase CMS domestically are an average of 28 percent bigger in terms of sales than non-purchasers in the same six-digit NAICS industry. Offshoring plants are even bigger, selling an average of more than double the sales of non-fragmenting plants. These results lead to a third fact:

Fact 3: Plants that purchase CMS are larger and more productive than plants with no purchases. 
In addition, plants that primarily offshore are larger and more productive than those that purchase CMS domestically.

Table 3: Plant means by contract manufacturing services purchase status

\begin{tabular}{|c|c|c|c|c|c|c|}
\hline & \multicolumn{3}{|c|}{ Raw Means } & \multicolumn{3}{|c|}{ Relative Ind. Means } \\
\hline & Sales $^{a}$ & Emp & $\ln (\mathrm{VAP})$ & Sales & Emp & $\ln (\mathrm{VAP})$ \\
\hline No Purchases & 19,487 & 51.3 & 4.51 & 0.87 & 0.91 & -0.03 \\
\hline Domestic Purchases & 37,077 & 79.8 & 4.63 & 1.28 & 1.20 & 0.07 \\
\hline Offshore Purchases & 51,457 & 137 & 4.74 & 2.17 & 1.69 & 0.20 \\
\hline All Plants & 24,686 & 60.4 & 4.55 & 1.00 & 1.00 & 0.00 \\
\hline
\end{tabular}

Notes: Relative ind. are means of plant values divided by NAICS 6 industry mean for sales and employment, and log differences for value-added labor productivity. All means weighted by the inverse probability of inclusion in the CMS sample. ${ }^{a}$ Sales in $\$ 000$ s.

Figure 2: Average plant sales by CMS puchase status, relative to industry mean

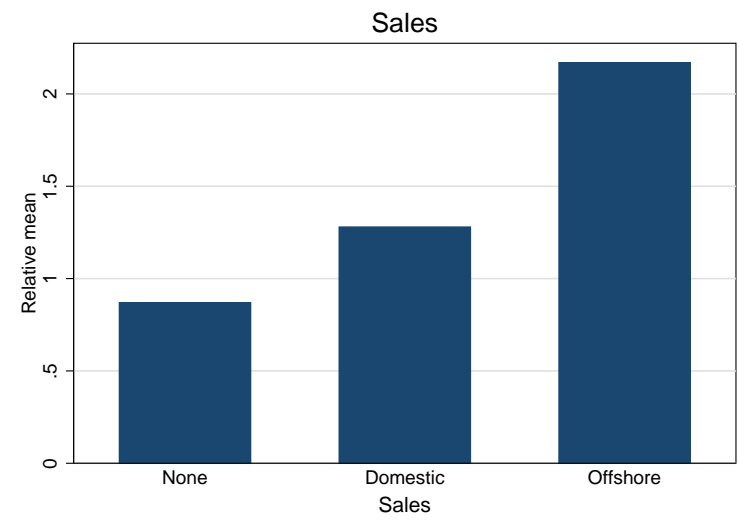

Notes: Figure depicts the average ratio of a plant's sales to mean sales in the plant's industry.

I also examine the extent to which within-industry variation in fragmentation relates to heterogeneity in plant use of technology. To do so, I regress a fragmentation (or offshoring) indicator on an industry-by-plant technology indicator. This yields an industry-specific estimate of the relationship between plant technology and fragmentation (or offshoring). Figure 3 plots these estimated industry-level technology coefficients against CAD intensity and skill intensity. Each graph displays the smoothed values with confidence bands of kernel-weighted local polynomial regressions of the industry-level estimates on industry characteristics. ${ }^{14}$ The left panel of Figure 3 a shows that the estimated relationship

\footnotetext{
${ }^{14}$ The standard errors for the confidence intervals in Figures 3 and 4 were calculated by taking a square root of the
} 
between technology and fragmentation is larger in more CAD-intensive industries. This is intuitive since CAD software allows firms to use electronic networks to communicate about design and production specifications. In contrast, the right panel shows that the probability that a fragmenting plant using communication technology will offshore is decreasing in industry CAD. The bottom panel depicts a non-monotonic relationship between the industry technology estimates for fragmentation and skill intensity, and a strongly decreasing relationship for the probability of offshoring. Table A.2 in the online appendix presents additional results from regressing these industry-specific technology estimates on these and other industry characteristics. Consistent with the patterns in Figure 3, the fragmentation industry technology estimates are increasing in CAD intensity, while the technology estimates of offshoring, conditional on fragmentation are decreasing in skill intensity.

Although the CMS data do not identify foreign sourcing locations, I use the linked import data to provide richer details on how country characteristics may relate to technology and offshoring. Figure $1 \mathrm{~b}$ plots the share of offshoring firms that source from a particular country against the share of those firms that use communication technology to control or coordinate shipments. The most popular sourcing country is China, with almost 80 percent of firms that purchase CMS offshore importing from China. Canada, Taiwan, and Germany are also important sourcing locations, with 40 to 60 percent of offshorers importing from each of them. The figure depicts a negative relationship between offshoring and technology shares, but this pattern is largely driven by firm size. Only the biggest firms select into the less popular locations, and these large firms also tend to use communication technology. ${ }^{15}$

The results in Figure 3 show that communication technology has a stronger relationship with offshoring in lower skill industries. Since industry skill requirements may also interact with supplier skill levels, I assess whether the relationship between technology and offshoring depends on country human capital. To do so, I regress an indicator equal to one if an offshoring firm sources from a particular country on industry-by-technology-by-country human capital tercile indicators, with middle skill countries as the omitted category. The industry-by-technology estimates are decreasing in

estimate of the conditional variance of the local polynomial estimator at each grid point. The conditional variance was estimated by: a) fitting a polynomial of a higher order locally by using a value of $1.5 \times$ the original bandwidth estimate; and $\mathrm{b}$ ) estimating the residual variance $\sigma^{2}\left(x_{0}\right)$ at each grid point, each of which were computed using the normalized weighted residual sum of squares from a local polynomial fit of a higher order. See StataCorp (2015) (pp. 1318-1321) for additional details on lpoly.

${ }^{15} \mathrm{In}$ an undisclosed analysis, I find that the negative relationship depicted in Figure $1 \mathrm{~b}$ is absent when controlling for firm sales. 
industry skill intensity for sourcing from low human capital countries. In contrast, the estimates are positively correlated with industry skill and CAD intensity for sourcing from high human capital countries. Figure 4 plots these estimates, which are suggestive of an important role for supplier skill in how firm-level communication technology affects sourcing decisions. Table A.2 in the online appendix presents results from regressing the estimates ex-post on industry characteristics. The table corroborates the message from Figure 4, and also shows that the industry-by-technology offshoring estimates for low human capital countries are decreasing in industry capital intensity but increasing in routineness. In contrast, the estimates for high human capital countries are increasing in capital intensity but decreasing in routineness.

The facts presented in this section highlight the importance of the extensive margin in plants' and firms' sourcing decisions. A large fraction of U.S. manufacturers do not fragment customized inputs. In addition, the majority of plants that do fragment production primarily source from domestic locations. The data also show considerable variation in manufacturers' sourcing decisions that is related to their use of communication technology in production. The empirical analysis will exploit this heterogeneity to explore the relationship more fully. 
Figure 3: Industry-level estimates of the relationship between plant technology and the probability of fragmentation and offshoring regressed on industry characteristics

(a) CAD Intensity
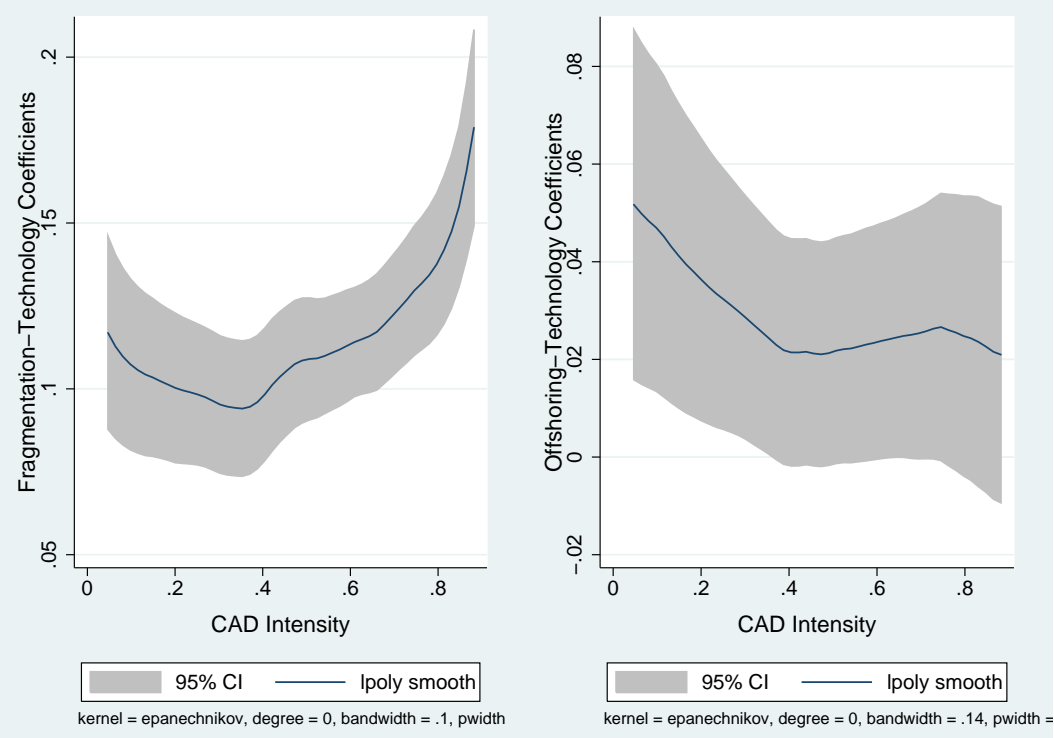

(b) Skill Intensity
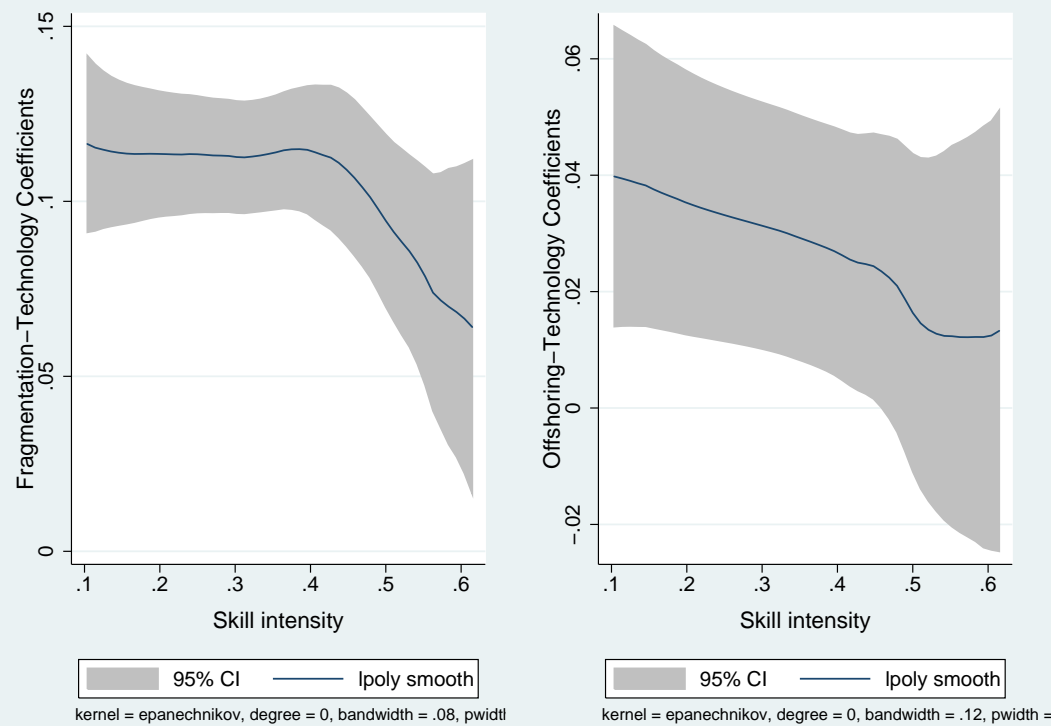

Notes: Figures display the smoothed values with confidence bands of kernel-weighted local polynomial regressions of industry-level estimates of the relationship between plant communication technology and fragmentation (or offshoring) on industry characteristics. Figures on the left correspond to estimated coefficients from regressing an indicator for fragmentation on an industry-specific plant communication technology indicator. Figures on the right correspond to estimated coefficients from regressing an indicator for offshoring, conditional on fragmentation on an industry-specific plant communication technology indicator. 
Figure 4: Industry-level estimates of the relationship between firm technology and the probability of offshoring from low and high human capital countries regressed on industry characteristics

(a) CAD Intensity

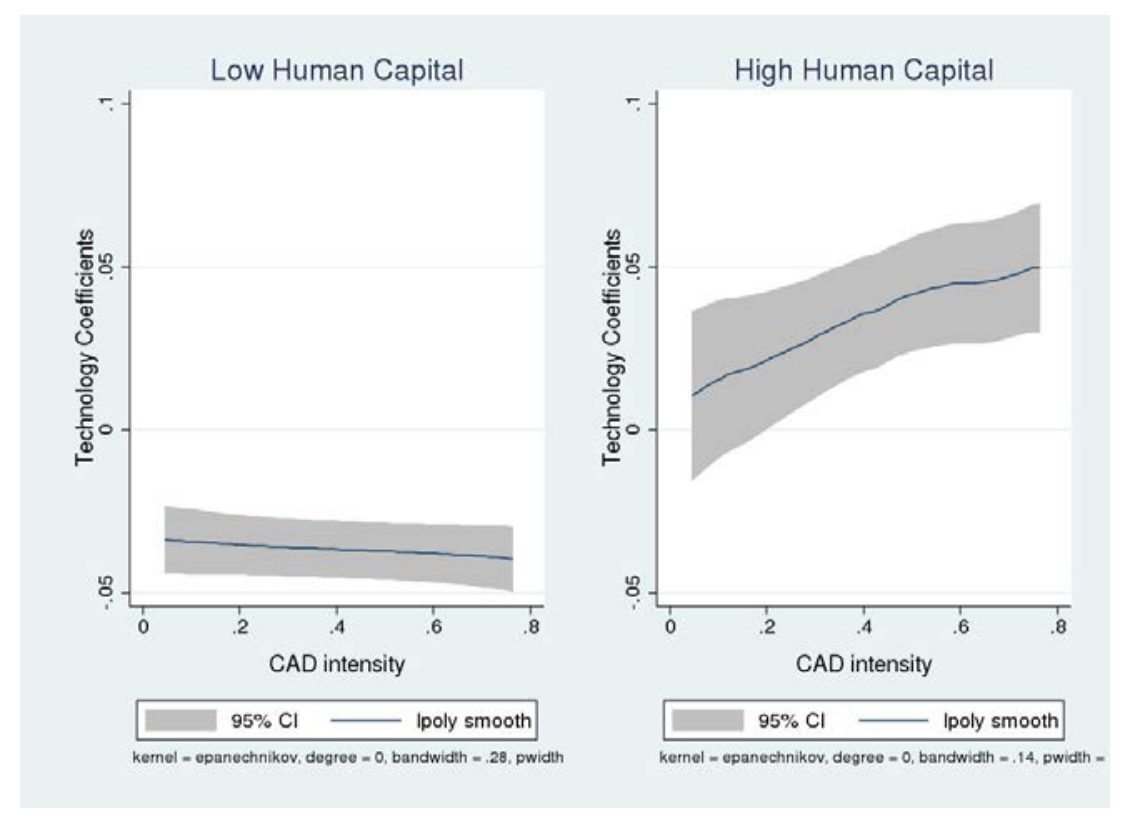

(b) Skill Intensity

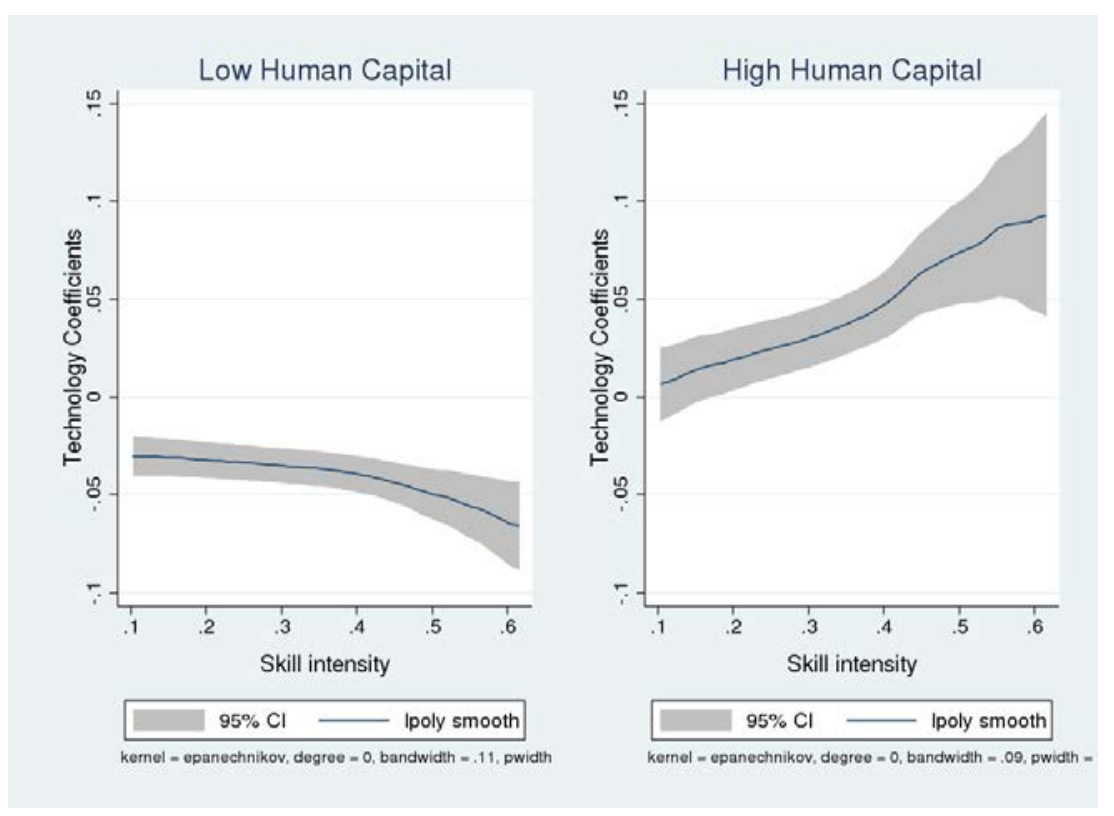

Notes: Figures display the smoothed values with confidence bands of kernel-weighted local polynomial regressions of industry-level estimates of the relationship between firm communication technology and offshoring from low and high human capital countries on industry characteristics. The estimated coefficients are from regressing an indicator for offshoring from a particular country on an industry-by-country-human-capital-tercile-specific firm communication technology indicator. Figures on the left plot the estimated relationship between firm communication technology and the probability of offshoring for low human capital countries. Figures on the right plot the estimated coefficients on the relationship between firm communication technology and the probability of offshoring for high human capital countries. 


\section{Theoretical motivation and empirical approaches}

In this section I present the potential theoretical channels through which technology may be related to fragmentation and offshoring. These channels motivate the three distinct empirical approaches that I implement.

\subsection{Theoretical channels that relate technology and fragmentation}

The main contribution of this paper is to document a role for communication technology in facilitating production fragmentation and offshoring. Before discussing the empirical strategy, it is helpful to review three potential theoretical mechanisms that might drive the relationship between technology and fragmentation.

First, technology may lower fragmentation costs. When different parts of the production process are performed in separate, distinct locations, firms need to coordinate across these locations. This coordination requires costly communication between suppliers and producers. Communication technology may lower the costs of coordinating and communicating across distances, thereby facilitating firms' ability to fragment production. This is the driving mechanism in a number of important models about offshoring (e.g., Grossman and Rossi-Hansberg, 2008; Antràs et al., 2008). While the focus of these models is on fragmentation across international borders, presumably the same coordination costs would affect domestic fragmentation. One might expect a disproportionate impact of technology on foreign vs. domestic sourcing- for example if coordination costs are increasing in distance- but that is ultimately an empirical question. ${ }^{16}$

A second theoretical channel that could give rise to a correlation between technology and fragmentation is based on the endogenous technology adoption models as in Melitz and Constantini (2008), Lileeva and Trefler (2010), Bustos (2011), and Boler et al. (2015). In these models, a trade shock may allow some firms to exploit new trade opportunities, leading to firm growth. Since technology adoption requires a fixed cost payment, the trade-induced firm growth makes it more likely that those firms will incur the fixed costs of technology adoption. Alternatively, a trade shock may induce some firms to upgrade their technology so that they grow enough to pay the fixed cost to trade. In both

\footnotetext{
${ }^{16}$ The online appendix presents an extension of the Melitz model that incorporates Grossman and Rossi-Hanbsberg type fragmentation costs with domestic or foreign sourcing.
} 
cases, trade and technology are complementary activities because they both lead firms to grow and entail fixed costs. In these frameworks, firm-level fragmentation and technology could be correlated not because technology lowers fragmentation costs, but because of common firm scale effects.

Finally, technology and fragmentation may be correlated due to a third factor, such as productivity or management ability. Better managers may be more adept at exploiting fragmentation opportunities and at adopting new technologies. If these factors are not controlled for in the analysis, then an observed correlation between technology and fragmentation may be spurious.

\subsection{Baseline approach}

I first estimate the relationship between fragmentation and technology controlling for additional factors, such as productivity, labor costs, and distance, that are likely to affect firms' sourcing decisions. I also estimate a specification with detailed geographical fixed effects to control for all regional unobservables. Specifically, I estimate:

$$
\operatorname{Pr}\left(y_{i, j, h}=1 \mid X_{i, j, h}\right)=\beta_{J}+\beta_{T} \text { Tech }_{i}+\beta_{w} \text { wage }_{h}+\sum \beta_{D} \text { Dist }_{i}+\sum \beta_{P} \text { Prod }_{i}
$$

where $y_{i, j, h}$ equals one if plant $i$ in industry $j$ and home state $h$ purchases CMS. Tech $i$ is a plant-level measure of communication technology. $w$ ge $_{h}$ is the producer's home state wage, Dist $i$ is a set of distance measures from plant $i$ to ports and borders, and Prod $i$ denotes plant productivity terciles. ${ }^{17}$ I measure productivity in terciles since the heterogeneous firm literature emphasizes the importance of productivity thresholds in trade and sourcing decisions. I include a full set of six-digit NAICS industry dummies as controls. Note that this approach is only cross-sectional, with no variation over time.

I also estimate a variant of equation (3.1) on the subset of plants that purchase CMS where $y_{i, j, h}$ equals one if plant $i$ in industry $j$ and home state $h$ purchases CMS offshore. This approach estimates the role of technology and other variables in a fragmenting plant's decision to source domestically or offshore. By focusing only on those plants that are fragmenting production, the analysis avoids confounding factors that influence a plant's decision to break up its production process across space with the decision on whether to source production offshore.

\footnotetext{
${ }^{17}$ These productivity terciles are not calculated within industries. In all specifications with industry fixed effects, the results using within industry productivity terciles are comparable.
} 
One potential concern with estimating equation (3.1) is that more productive plants may reside in the most productive states. To address the potential for unobservable regional characteristics to bias the estimates, I add fixed effects for each of the Bureau of Economic Analysis (BEA) economic areas to equation (3.1). There are 179 of these economic areas which are based on the relevant regional markets surrounding metropolitan and micropolitan statistical areas. Although these fixed effects preclude a meaningful assessment of the role of labor costs and distance, they ensure that the estimated relationship between fragmentation and technology is not biased by regional variation.

As discussed above, another potential concern with estimating equation (3.1) is that a shock to fragmentation may induce firms to upgrade their technology so that they can exploit the new sourcing opportunities. If new technology only affects fragmentation decisions through its impact on firm size, then $\beta_{T}$, the estimated coefficient on technology, will not necessarily reflect a cost-lowering effect. I therefore perform a robustness test in which I control for plant size using a continuous rather than discrete productivity measure. I also control for plant size using sales rather than productivity to minimize the possibility that $\beta_{T}$ simply reflects the scale effect predicted by endogenous technology adoption models.

\subsection{Difference-in-difference approach}

Estimating equation (3.1) via OLS to identify the role of communication technology on fragmentation and offshoring still raises two major concerns. First, there is the potential for reverse causality between a plant's fragmentation status and its use of communication technology in production. If communication technology lowers fragmentation costs, then a shock to fragmentation may induce firms to adopt new technologies that facilitate fragmentation. This type of simultaneity would lead to an upward bias on $\beta_{T}$, the estimated effect of communication technology. Second, as noted above, plant use of communication technology may be correlated with unobservable plant characteristics that could lead to a spurious correlation between technology and fragmentation. Although I control for productivity and size in the analysis, these variables may not fully capture heterogeneity in other factors such as managerial ability.

In light of these challenges, I focus on identifying a specific channel through which a plant's communication technology may affect its sourcing decisions. Conversations with suppliers at CMS 
trade shows indicated that the ability to communicate electronically has lowered fragmentation costs more in industries in which production specifications are readily codified in an electronic format. Specifically, practitioners in industries that use Computer-aided design (CAD) and Computer Aided Manufacturing (CAM) software intensively described significant fragmentation cost savings from the ability to communicate electronically. For example, a gasket producer described costs that fell from "hundreds of dollars to cents" when CAD files that could be plugged into CAM programs replaced conventional drawings, sent via fax, that required additional verbal communication to interpret. In contrast, producers in industries in which the production process is not compatible with CAD/CAM software did not experience these savings. ${ }^{18}$ They have also switched from fax to email, or even to online systems for order placements, but how they communicate design specifications and the production process itself still represents a significant fragmentation cost.

Estimating a differential impact of electronic networks that varies systematically with industrylevel electronic codifiability provides evidence that technology lowers fragmentation costs by facilitating communication about design specifications. This approach is similar to the identification strategy in Rajan and Zingales (1998), who assess the effect of financial development on country growth by estimating a differential impact of financial development that is increasing in an industry's reliance on external financing. ${ }^{19}$ Specifically, I exploit the plant and industry-level variation in the data to estimate

$$
\begin{array}{r}
\operatorname{Pr}\left(y_{i, j, h}=1 \mid X_{i, j, h}\right)=\beta_{J}+\beta_{T} \text { Tech }_{i}+\beta_{T \times C A D} \text { Tech }_{i} \times C A D_{j}+ \\
\beta_{w} \text { wage }_{h}+\sum \beta_{D} \text { Dist }_{i}+\sum \beta_{P} \text { Prod }_{i},
\end{array}
$$

where $\beta_{T \times C A D}$ is the coefficient on the interaction between plant $i$ 's use of networks and industry $j$ 's CAD/CAM intensity. Note that I do not include industry CAD directly since it is subsumed by the industry fixed effects. This is comparable to a difference-in-difference approach, where industry codi-

\footnotetext{
${ }^{18}$ For example, a spring manufacturer explained that he could not use CAM software because his industry requires continuous process manufacturing, which is a production technique that cannot be implemented via CAD/CAM. These conversations took place at the Mid-Atlantic Design-2-Part Show in Phoenixville, PA on April 14, 2011.

${ }^{19}$ One important distinction between this approach and Rajan and Zingales (1998) is that those authors exploit variation across countries and industries, while in this context every plant belongs to just one industry. Nevertheless, the same logic should apply here. If technology lowers the costs of communicating specifications to suppliers, we would expect to a see larger effect in more CAD-intensive industries.
} 
fiability represents a continuous treatment variable. The coefficient $\beta_{T \times C A D}$ shows how technology's impact depends on the extent to which industry-level production specifications can be transmitted electronically.

It is important to be clear about what this approach can and cannot identify. Since it does not exploit an exogenous shock to communication technology and is based solely on cross-sectional evidence, it does not allow me to quantify the extent to which technology has increased fragmentation over time or across plants. Despite this limitation, the approach sheds light on whether communication technology lowers fragmentation costs. Even if the reverse causality story is at play so that firms are responding to a fragmentation shock by adopting technology, we would only expect $\beta_{T \times C A D}$ to be positive and significant if they expect greater cost savings in high CAD industries (i.e., those industries in which the production process can be transmitted electronically). In contrast, it is unlikely that a fragmentation shock would have had a bigger effect on firm size in the CAD-intensive industries (the scale effect described above), or that firms in CAD-intensive industries have better management ability (or other omitted variable that could drive a spurious correlation).

\subsection{First difference approach}

Finally, I exploit time series variation available for a subset of plants to control for all plant-level unobservables that are constant over time. The CMS data are only available in 2007, but similar fragmentation data are available for a subset of firms in 2002. In particular, the 2002 CM asked establishments whether they contracted with another firm for their production. ${ }^{20}$ This information makes it feasible to construct a panel of CMS purchases for single unit firms. Because the 2002 question does not distinguish between domestic and foreign sourcing, I cannot use it to assess how technology affects offshoring.

I use the panel data to estimate the probability that plant $i$ in industry $j$ and year $t$ purchases CMS via

$$
\operatorname{Pr}\left(y_{i j t}=1 \mid X_{i j t}\right)=\beta_{I}+\beta_{T} \text { Tech }_{i t}+\beta_{P} \operatorname{Prod}_{i t}+\beta_{t},
$$

\footnotetext{
${ }^{20}$ The exact question as it appeared on the Census form is presented in the appendix.
} 
where the $\beta_{I}$ are coefficients on plant fixed effects. $\beta_{t}$ is the coefficient on an indicator for year, where 2002 is the omitted category. With two time periods and plant fixed effects, this approach is identical to a first difference estimation and controls for all unobserved plant-level hetereogeneity that is constant over time. I also assess the interaction between plant technology and industry CAD/CAM intensity in the panel and estimate

$$
\operatorname{Pr}\left(y_{i j t}=1 \mid X_{i j t}\right)=\beta_{I}+\beta_{T} T e c h_{i t}+\beta_{T \times C A D} \operatorname{Tech}_{i t} \times C A D_{j}+\beta_{P} \operatorname{Prod}_{i t}+\beta_{t} .
$$

Note that in this specification, plant use of technology is time-varying, but industry CAD/CAM intensity is not. ${ }^{21}$

\subsection{Additional variables}

I measure variation in industry electronic codifiability as the share of plants in a six-digit NAICS industry that used CAD and CAM software in 1999, calculated from the CNUS data. Industry variation in the level of CAM intensity is largely driven by inherent differences in the industry-level production process, some of which are amenable to being codified electronically (e.g., car parts) and some which are not (e.g., continuous form manufacturing). While CAD can be used widely, it is more prevalent in industries with complicated design and production processes that therefore benefit more from electronic codification. CAD intensity ranges from almost zero to one, with a mean of 0.44 and standard deviation of 0.25 . The least CAD/CAM intensive industries are food manufacturing and textiles, while automotive, aerospace, and machinery manufacturing are all high CAD/CAM. Consistent with the premise that it facilitates communication about design specifications, the correlation coefficient between CAD intensity and the fraction of plants in an industry using electronic networks to share product designs with suppliers is 0.5. Additional details on the CAD measure are in the online appendix.

A plant's potential to save on labor costs is measured by state-industry level U.S. wages constructed

\footnotetext{
${ }^{21}$ It would be ideal to have time-series variation in CAD driven by exogenous changes in industry-level production processes. This would provide more power to identify an effect, and could provide causal evidence of technology changes on fragmentation changes. Unfortunately, I could not find such an exogenous shock, and the Census only asked about CAD/CAM use in the 1999 CNUS. The current approach therefore provides evidence that technology adoption is related to changes in fragmentation, but does not necessarily imply that changes in technology caused changes in fragmentation.
} 
from the Bureau of Labor Statistics' Occupation Employment Statistics (OES). To minimize any potential bias arising from the relationship between wages and skill, the wage measure is based solely on production worker occupations, and the weights of these occupations for a given industry are national averages and therefore fixed across states. As a result, the variation in wages across states is driven by differences in states' wages for six-digit occupations, and not by compositional differences in the concentrations of occupations across states. ${ }^{22}$ Averaged over industry, the mean state wage is $\$ 14.58$, with a standard deviation of $\$ 1.08$.

$D i s t_{i}$ is a vector of distances between plant $i$ and potential domestic and foreign sourcing locations. Proximity to domestic suppliers is the distance between a plant and the closest manufacturing service provider (MSP). I identify MSPs as all manufacturing establishments in the 2007 CM that specify their primary activity as "Providing contract manufacturing services to others." 23 Fragmenting plants are an average of 1.6 miles away from an MSP compared to 2.2 miles for plants with no CMS purchases. Distances to potential foreign sourcing locations are measured as the distance to the closest deep water port, the closest border crossing with Canada, and the closest crossing with Mexico. On average, plants that purchase CMS offshore are 50 miles closer to a deep water port and 80 miles closer to a Mexican border crossing relative to plants that purchase CMS domestically. To allow for the importance of highly localized shipments documented in Hillberry and Hummels (2008), I use discrete bins for these distances in the empirical specification.

I construct productivity terciles using the log of plants' value-added labor productivity. I use terciles to allow for the non-linearities predicted by heterogeneous firms models, where firms face a productivity threshold above which profits from fragmentation exceed profits from integrated production. I also use a continuous measure of the log of plants' value-added labor productivity in a robustness test.

Communication technology is an indicator for whether a plant used electronic networks to control or coordinate shipments. As explained in section 2 , this variable is a valid proxy for whether a plant has integrated electronic communication in its production process.

\footnotetext{
${ }^{22}$ Skill differences across occupations are a bigger problem than differences within occupations. Handwerker and Spletzer (2010) find that the majority of wage differences within plants are driven by differences across occupations.

${ }^{23}$ The $2007 \mathrm{CM}$ asked all plants in the CMS sample to identify their primary activity from four choices. "Providing contract manufacturing services to others" is one of the four options.
} 


\section{Results on fragmentation and offshoring}

This section presents results from estimating the relationship between technology and fragmentation via OLS. In the appendix I show that the main estimates are robust in an instrumental variable approach and when estimated via nested logit.

\subsection{Main results}

Table 4 presents results from estimating equations (3.1) and (3.3). The left panel provides estimates for the probability of fragmentation and the right panel corresponds to the probability of offshoring, conditional on fragmentation. The first column in each panel depicts a large and statistically significant relationship between a plant's use of electronic networks to coordinate shipments and its decision to fragment production and offshore. Plants using networks are 9.7 percentage points more likely to fragment production. Of the plants that fragment production, the probability of offshoring is 2.3 points higher for plants using electronic networks. The second column in each panel adds fixed effects for the 179 BEA economic areas. In both cases, the estimated coefficient on plant technology is virtually unchanged.

The last column in each panel of Table 4 presents estimates in which a plant's use of networks is interacted with its industry CAD/CAM intensity. In column 3, the estimated interaction effect is positive and significant, indicating a differential impact across industries. Relative to plants that do not use electronic networks, plants that use networks in "other apparel" manufacturing (CAD intensity of 4 percent) are only 7.5 percentage points more likely to fragment, while plants using networks in the "semiconductor machinery" manufacturing (CAD intensity of 98 percent) are over 13 points more likely to fragment. The differential impact of electronic networks between these two industries is thus about 5.7 percentage points, about 20 percent of the average share of fragmentation. These results point to an economically important role for integrating electronic communication into the production process as a means to lower the costs of communicating design and production specifications across locations.

While the probability of fragmentation is increasing in industry CAD intensity, the conditional probability of offshoring is not. The last column of Table 4 shows that the coefficient on the interaction 
Table 4: OLS estimates of the probability of fragmentation and offshoring

Dependent variable is an indicator equal to one if plant $i$ :

\begin{tabular}{|c|c|c|c|c|c|c|}
\hline & \multicolumn{3}{|c|}{ Fragments Production } & \multicolumn{3}{|c|}{ Offshores | Fragmentation } \\
\hline & 1 & 2 & 3 & 4 & 5 & 6 \\
\hline $\begin{array}{l}\text { Elec. networks } s_{i} \\
\quad \times \ln \left(C A D_{j}\right)\end{array}$ & $\begin{array}{c}0.097^{* * *} \\
(0.004)\end{array}$ & $\begin{array}{c}0.096^{* * *} \\
(0.004)\end{array}$ & $\begin{array}{c}0.072^{* * *} \\
(0.009) \\
0.060^{* * *} \\
(0.019)\end{array}$ & $\begin{array}{c}0.023^{* * *} \\
(0.004)\end{array}$ & $\begin{array}{c}0.024^{* * *} \\
(0.004)\end{array}$ & $\begin{array}{c}0.035^{* * *} \\
(0.013) \\
-0.026 \\
(0.022)\end{array}$ \\
\hline $\ln \left(\right.$ wage $\left._{h}\right)$ & $\begin{array}{c}0.188^{* * *} \\
(0.028)\end{array}$ & $\begin{array}{c}0.052 \\
(0.058)\end{array}$ & $\begin{array}{c}0.053 \\
(0.057)\end{array}$ & $\begin{array}{c}-0.093^{* * *} \\
(0.026)\end{array}$ & $\begin{array}{c}-0.089^{*} \\
(0.049)\end{array}$ & $\begin{array}{c}-0.089^{*} \\
(0.049)\end{array}$ \\
\hline $\ln \left(\operatorname{VAProd}_{i}\right) \mathrm{Q} 2$ & $\begin{array}{c}0.044^{* * *} \\
(0.005)\end{array}$ & $\begin{array}{c}0.043^{* * *} \\
(0.005)\end{array}$ & $\begin{array}{c}0.043^{* * *} \\
(0.005)\end{array}$ & $\begin{array}{c}0.007^{* *} \\
(0.004)\end{array}$ & $\begin{array}{c}0.007^{* *} \\
(0.004)\end{array}$ & $\begin{array}{c}0.007^{* *} \\
(0.004)\end{array}$ \\
\hline Q3 & $\begin{array}{c}0.077^{* * *} \\
(0.006)\end{array}$ & $\begin{array}{c}0.076^{* * *} \\
(0.006)\end{array}$ & $\begin{array}{c}0.077^{* * *} \\
(0.006)\end{array}$ & $\begin{array}{c}0.028^{* * *} \\
(0.005)\end{array}$ & $\begin{array}{c}0.028^{* * *} \\
(0.005)\end{array}$ & $\begin{array}{c}0.028^{* * *} \\
(0.005)\end{array}$ \\
\hline MSP 5-20 miles away & $\begin{array}{c}-0.020 * * * \\
(0.005)\end{array}$ & $\begin{array}{c}-0.016^{* * *} \\
(0.005)\end{array}$ & $\begin{array}{c}-0.016^{* * *} \\
(0.005)\end{array}$ & $\begin{array}{c}0.005 \\
(0.006)\end{array}$ & $\begin{array}{c}0.004 \\
(0.006)\end{array}$ & $\begin{array}{c}0.004 \\
(0.006)\end{array}$ \\
\hline $20+$ miles away & $\begin{array}{l}-0.016 \\
(0.011)\end{array}$ & $\begin{array}{l}-0.009 \\
(0.011)\end{array}$ & $\begin{array}{c}-0.009 \\
(0.011)\end{array}$ & $\begin{array}{c}0.000 \\
(0.016)\end{array}$ & $\begin{array}{c}0.001 \\
(0.016)\end{array}$ & $\begin{array}{c}0.001 \\
(0.016)\end{array}$ \\
\hline Port 51-200 miles & $\begin{array}{c}-0.017 * * * \\
(0.004)\end{array}$ & $\begin{array}{c}-0.023^{* * *} \\
(0.006)\end{array}$ & $\begin{array}{c}-0.023^{* * *} \\
(0.006)\end{array}$ & $\begin{array}{l}-0.006 \\
(0.005)\end{array}$ & $\begin{array}{l}-0.011 \\
(0.008)\end{array}$ & $\begin{array}{l}-0.011 \\
(0.008)\end{array}$ \\
\hline $200+$ miles away & $\begin{array}{c}0.001 \\
(0.005)\end{array}$ & $\begin{array}{c}-0.023^{* *} \\
(0.011)\end{array}$ & $\begin{array}{c}-0.023^{* *} \\
(0.011)\end{array}$ & $\begin{array}{c}-0.016^{* * *} \\
(0.004)\end{array}$ & $\begin{array}{l}-0.011 \\
(0.013)\end{array}$ & $\begin{array}{l}-0.011 \\
(0.013)\end{array}$ \\
\hline $50+$ miles to Mexico & $\begin{array}{l}-0.016 \\
(0.012)\end{array}$ & $\begin{array}{c}0.004 \\
(0.029)\end{array}$ & $\begin{array}{c}0.003 \\
(0.029)\end{array}$ & $\begin{array}{c}-0.096^{* * *} \\
(0.018)\end{array}$ & $\begin{array}{l}-0.036 \\
(0.053)\end{array}$ & $\begin{array}{l}-0.036 \\
(0.053)\end{array}$ \\
\hline $50+$ miles to Canada & $\begin{array}{l}-0.010 \\
(0.008)\end{array}$ & $\begin{array}{l}-0.024^{*} \\
(0.014)\end{array}$ & $\begin{array}{c}-0.025^{*} \\
(0.014)\end{array}$ & $\begin{array}{c}-0.011^{*} \\
(0.006)\end{array}$ & $\begin{array}{l}-0.016 \\
(0.013)\end{array}$ & $\begin{array}{l}-0.016 \\
(0.013)\end{array}$ \\
\hline NAICS 6 Fixed Effects & yes & yes & yes & yes & yes & yes \\
\hline Regional Fixed Effects & no & yes & yes & no & yes & yes \\
\hline Adj. $R^{2}$ & 0.09 & 0.09 & 0.09 & 0.08 & 0.09 & 0.09 \\
\hline $\mathrm{N}$ & 105,500 & 105,500 & 105,500 & 30,700 & 30,700 & 30,700 \\
\hline
\end{tabular}

Notes: The left panel corresponds to estimates of the probability that plant purchases CMS. The right panel corresponds to estimates of the probability that a plant purchasing CMS does so from foreign suppliers. CAD is the CAD/CAM intensity in a plant's industry. MSP denotes manufacturing service provider. Standard errors clustered by industry. *, **, *** denote $10 \%, 5 \%$ and $1 \%$ significance respectively. $\mathrm{N}$ rounded for disclosure avoidance.

term is negative (though not significant). Plant use of networks is associated with a higher probability that a fragmenting plant will source offshore, but the effect is stronger and statistically significant only for plants in low CAD industries, and weaker (or zero) for those in the highest CAD industries. Figure A.1 in the online appendix plots the full effect of electronic networks on the probabilities of fragmentation and offshoring evaluated at different levels of CAD intensity. Since CAD/CAM 
is a primary means by which firms can exploit electronic networks to communicate about design specifications, this result suggests that technology's ability to lower coordination costs is larger for domestic sourcing relative to offshoring. ${ }^{24}$

The results also point to an important role for productivity, distance, and local labor costs in a firm's fragmentation decision. Column 1 of Table 4 shows that plants in the second productivity tercile are 4.4 percentage points more likely to fragment than the least productive plants, and those in the top tercile are 7.7 points more likely to fragment. The estimated coefficients are significant at the one percent level with a statistically significant difference between them. The right panel of Table 4 shows that, of the plants that fragment production, those in the top productivity tercile are 2.8 points more likely to source offshore. These results are consistent with predictions from a heterogeneous firms model with fixed costs to fragment production that are higher for foreign sourcing.

The OLS estimated coefficient on the state wage reported in column 1 of Table 4 is 0.188 and significant at the one percent level. Its magnitude implies that a plant in Washington state is 4.8 percentage points more likely to fragment production than an otherwise identical plant in Mississippi, where average production worker wages are almost 30 percent lower. The right panel of Table 4 shows that a plant fragmenting production in Mississippi is 2.4 points more likely to source offshore than a comparable fragmenting plant in Washington. More generally, the likelihood of foreign sourcingconditional on fragmentation-is decreasing in the local wage. This result may reflect the fact that firms in low wage states must source offshore to lower their labor costs: a plant in Mississippi cannot lower its wage rate by fragmenting in the U.S. ${ }^{25}$

Table 4 also documents an important role for distance in plants' sourcing strategies. Relative to plants that have a manufacturing service provider (MSP) within a five mile radius, plants that are 5-20 miles away from the closest MSP are 2.0 percentage points less likely to fragment production.

\footnotetext{
${ }^{24}$ This result also supports the premise that the differential impact of plant technology across industries is not driven by a spurious correlation with a plant's manager's ability. If industry CAD/CAM were systematically related to better managers, one would expect that the relationship between offshoring and technology would also be increasing in industry $\mathrm{CAD}$, since offshoreres tend to be the largest and most productive establishments.

${ }^{25}$ Recall that the specification for the probability of offshoring is conditional on fragmentation. In an unconditional regression of the probability of offshoring, the estimated wage coefficient is small and statistically insignificant. These estimates (available upon request) are consistent with the option to fragment domestically being an important factor in firms' decisions to offshore. Under the cost assumptions presented in the model in the online appendix, the local wage should not affect the offshoring decision, instead the relevant comparison is of the wage in the optimal domestic sourcing location relative to the foreign wage.
} 
The probability that a fragmenting plant will source offshore is unrelated to its distance from an MSP, but plants that do fragment are 1.6 points less likely to offshore if they are over 200 miles from a port. Proximity to Mexico is also related to offshoring decisions. Plants that purchase CMS are 9.6 points less likely to source from a foreign location if they are more than 50 miles away from a Mexican border crossing.

\subsection{Robustness}

The positive and significant interaction between plant technology and industry CAD intensity supports the premise that technology lowers the costs associated with communicating about design and product specifications. However, one might still worry that plant scale is an important determinant of both a plant's technology and sourcing decisions. To address this concern, Table 5 presents results from estimating equation (3.1) with a continuous measure of productivity (columns 1 and 4) and with the $\log$ of sales (columns 2 and 5). Both variables have a positive and significant relationship with fragmentation and offshoring that is similar to the relationship depicted by the productivity terciles. Most importantly, the estimated coefficient on communication technology remains positive and significant. The magnitude decreases most when using sales, but still implies that plants using networks are 8.0 points more likely to purchase CMS, and conditional on fragmenting, 1.7 points more likely to offshore. 


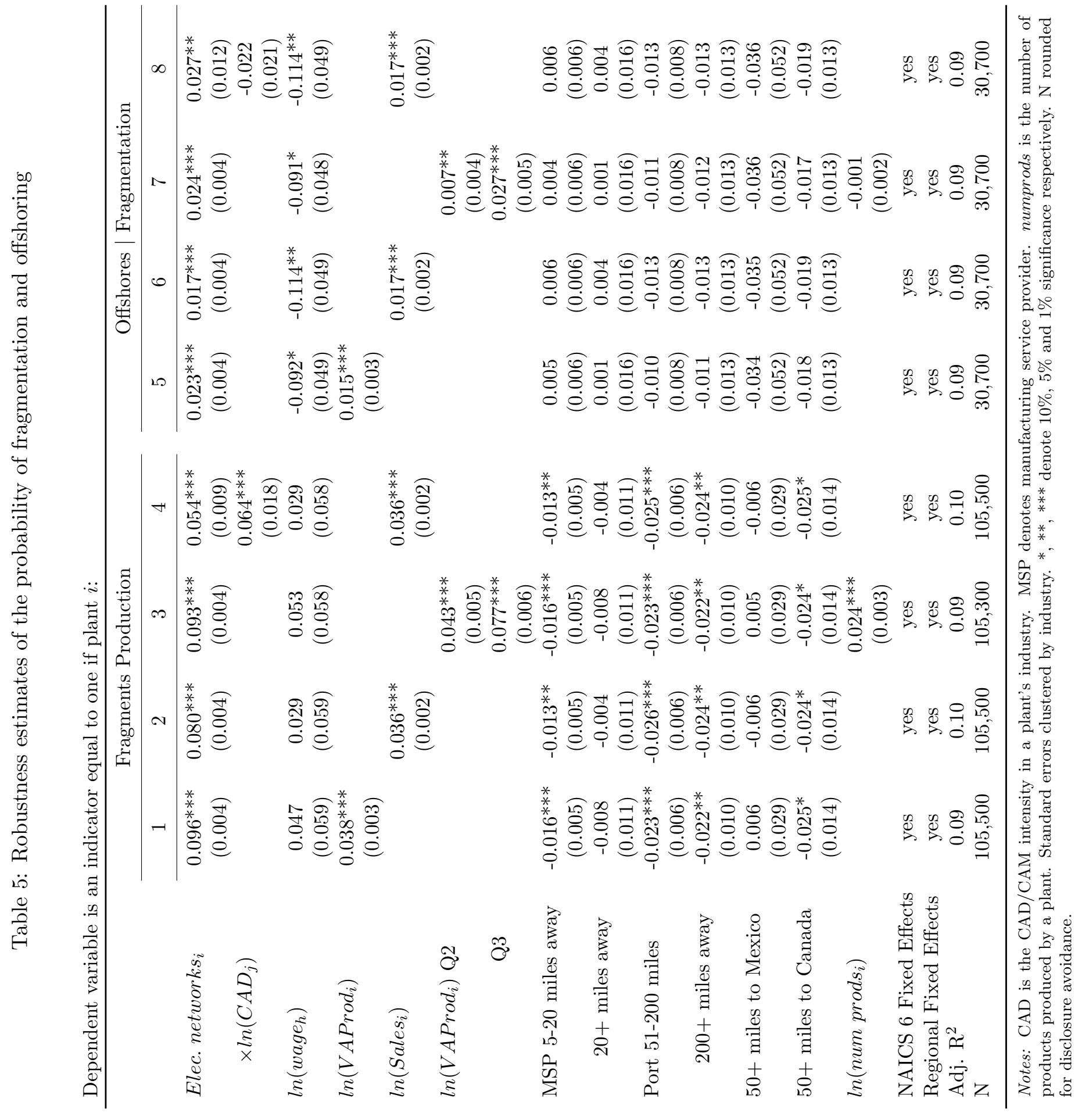


Another potential concern is that larger plants may be more likely to fragment production and offshore simply because they sell more distinct products and therefore require more inputs. Columns 3 and 6 in Table 5 show that the estimated coefficients on electronic networks are virtually unchanged when controlling for the log of the number of products sold by an establishment. In column 3 , the estimated coefficient on the number of products implies that a plant with twice as many products is 2.4 points more likely to purchase CMS, while the coefficient in column 7 suggests no relationship between the number of products produced and the likelihood of purchasing CMS offshore.

All the results presented thus far are based on OLS estimates. Since the CMS data are discrete, a non-linear probability model may be more appropriate. In the appendix, I show that the main results are robust in a nested logit specification in which firms decide between fragmentation or not in the top tier, and then between domestic or foreign sourcing in the second tier. Figure A.1 in the appendix depicts the nesting structure. Plants using networks are 10 percentage points more likely to fragment production. Figure A.2 plots the average marginal effects of network use by industry CAD intensity. Panel (b) shows that the estimated effect of domestic fragmentation is increasing in industry CAD intensity. In contrast, panel (d) shows that the effect on offshoring conditional on fragmentation is decreasing in industry CAD. These results are both consistent with the OLS estimates.

The appendix also presents results from instrumenting for a plant's use of technology in 2007 using its technology in 2002. An IV approach is useful both for addressing the possibility of reverse causality, and for mitigating potential measurement error attenuation bias from using a proxy variable for plant communication technology. I implement the IV using each plant's 2002 use of electronic networks and productivity as instruments. Table A.4 presents the IV estimates, which are larger than the OLS results and still statistically significant. Most importantly, the "Adopters" column in each panel shows that the IV estimates are robust when the sample is limited to the subset of plants that did not fragment production in 2002. Limiting the analysis to this subsample ensures that past technology use was not driven by past fragmentation.

In the online data appendix, I also show that the estimated wage and distance results are robust to: a) controlling for local demand differences using personal income in a plant's BEA economic area; b) controlling for skill differences across states using the share of workers with a college degree; and c) using the weighted distance to each plant's input suppliers as an alternative domestic distance 
measure. $^{26}$

\subsection{Panel results}

The results presented thus far are all based on cross-sectional variation in technology and fragmentation. To control for plant-level factors that are constant over time, I use the panel of single-unit firms to assess how changes in communication technology relate to changes in CMS purchases.

Table 6 presents results from using the panel data to estimate equation (3.3) with plant fixed effects. Column 1 shows that plants that begin using electronic networks to control or coordinate shipments are 3.3 points more likely to fragment production. Columns 2 and 3 show that this result is robust to controlling for changes in plant productivity and only slightly smaller when controlling for changes in sales, in which case it implies that adoption of technology is related to a 3.1 increase in the probability of fragmentation. To put this point estimate in context, fragmentation increased 13.4 percent in this sample from 2002 to $2007 .{ }^{27}$ Columns 4 and 5 present results in which the plant-level technology indicator is interacted with industry CAD intensity. The interaction term is positive and significant at the ten percent level in column 4. It is slightly smaller and no longer significant in column 5 when plant sales are included. Since the CAD intensity measure is based on 1999 data, it is time-invariant and therefore has less power in the first difference specification. It is reassuring that the same basic pattern is present, even if it is only significant without plant sales.

The cross-sectional and panel data all show an important role for communication technology in plants' sourcing decisions. Plants that have integrated electronic communication into their production process are more likely to purchase CMS and offshore. In addition, the effect of plant communication technology is stronger in CAD-intensive industries in which it is feasible for plants to use technology for communicating design specifications. Perhaps somewhat surprisingly, however, the impact of plant technology on the probability that a fragmenting plant will offshore is decreasing in industry CAD

\footnotetext{
${ }^{26}$ I identify a plant's input suppliers based on the plant's industry and the requisite inputs in that industry according to the 2002 BEA input-output table, using expenditure shares on each input as weights. Prior working paper versions of the paper also show that the results are robust to controlling for: a) manufacturing concentration using the share of manufacturing employment to population in a state; and b) endogenous plant location by using the subset of plants that have existed in the same physical location for at least ten years.

${ }^{27}$ It is important to note that these results do not necessarily imply that changes in firm use of communication technology caused changes in fragmentation. For example, it is also possible that a positive shock to fragmentation induced firms to adopt new technologies in order to take advantage of the new fragmentation opportunities.
} 
Table 6: Panel regression of the probability of fragmentation

\begin{tabular}{lccccc}
\multicolumn{6}{c}{ Dependent variable is one if plant $i$ in industry $j$ and year $t$ purchases CMS } \\
\hline & 1 & 2 & 3 & 4 & 5 \\
\hline Elec. networks $i t$ & $0.033^{* * *}$ & $0.033^{* * *}$ & $0.031^{* * *}$ & 0.011 & 0.012 \\
& $(0.007)$ & $(0.007)$ & $(0.007)$ & $(0.012)$ & $(0.012)$ \\
$\quad \times \ln \left(\right.$ CAD $\left._{j}\right)$ & & & & $0.050^{*}$ & 0.044 \\
& & & & $(0.027)$ & $(0.027)$ \\
$\ln \left(\right.$ V AProd $\left._{i t}\right)$ & & -0.001 & & -0.002 & \\
& & $(0.005)$ & & $(0.005)$ & \\
$\ln \left(\right.$ Sales $\left._{i t}\right)$ & & & $0.034^{* * *}$ & & $0.033^{* * *}$ \\
\multirow{2}{*}{ Year is 2007} & $0.028^{* * *}$ & $0.028^{* * *}$ & $0.019^{* * *}$ & $0.028^{* * *}$ & $0.019^{* * *}$ \\
& $(0.004)$ & $(0.004)$ & $(0.004)$ & $(0.006)$ & $(0.006)$ \\
Constant & $0.264^{* * *}$ & $0.270^{* * *}$ & -0.020 & $0.271^{* * *}$ & -0.016 \\
\multirow{2}{*}{$\mathrm{N}$} & $(0.002)$ & $(0.021)$ & $(0.048)$ & $(0.020)$ & $(0.048)$ \\
& 60,700 & 60,700 & 60,700 & 60,700 & 60,700 \\
\hline
\end{tabular}

Notes: Sample is a balanced panel of single-unit firms. Standard errors clustered by industry. $*, * *, * * *$ denote $10 \%, 5 \%$ and $1 \%$ significance respectively. $\mathrm{N}$ rounded for disclosure avoidance.

intensity. This result suggests that plant technology may lower communication costs more for domestic sourcing relative to offshoring. In the next section, I assess the extent to which differences in human capital across countries can rationalize this finding.

\section{Multi-country sourcing decisions}

In this section, I exploit the linked CMS-import data to assess whether a firm's ability to exploit technology to lower coordination costs depends upon potential suppliers' human capital. I first establish the fact that offshoring firms import disproportionately more from low-income countries, which also tend to have low human capital. I then show that the relationships between offshoring and firm communication technology, industry CAD/CAM intensity, and the differential impact of firm technology across industry CAD/CAM intensity are all increasing in country human capital.

\subsection{Offshoring and country income}

To calculate the extent to which offshoring firms source disproportionately more from low-wage countries, I aggregate the import data to the firm-country level and classify countries as low wage if they 
are in the bottom two terciles of per-capita GDP. ${ }^{28}$ I regress the fraction of each firm's imports from low-wage countries on indicators for firms' CMS purchase status. No purchases is the omitted category. Since offshoring firms tend to be larger and more productive, and larger firms tend to source from more markets (e.g., Bernard et al., 2009; Yeaple, 2009), it is important to control for firm size.

Table 7 presents the results controlling for firm size using log sales (columns 1 and 2) or the log of value-added labor productivity (columns 3 and 4). Columns 2 and 4 include the log of total imports as an additional control for size. All specifications include fixed effects for the firm's modal industry. Across all specifications, the estimated coefficient for offshoring firms ranges from 0.158 to 0.204 and is significant at the 99 percent level. Offshoring firms source 16 to 20 percentage points more from low-wage countries relative to non-CMS purchasers. They also import relatively more from low-wage countries than firms that purchase CMS domestically.

Table 7: Fraction of imports from low-income countries, as a function of CMS purchase status

\begin{tabular}{|c|c|c|c|c|}
\hline & 1 & 2 & 3 & 4 \\
\hline \multicolumn{5}{|l|}{ CMS purchases are } \\
\hline Domestic & $\begin{array}{c}-0.008^{* *} \\
(0.004)\end{array}$ & $\begin{array}{l}-0.004 \\
(0.004)\end{array}$ & $\begin{array}{l}-0.003 \\
(0.004)\end{array}$ & $\begin{array}{c}-0.010^{* *} \\
(0.004)\end{array}$ \\
\hline Domestic \& Offshore & $\begin{array}{l}0.033^{*} \\
(0.018)\end{array}$ & $\begin{array}{c}0.023 \\
(0.018)\end{array}$ & $\begin{array}{c}0.077^{* * *} \\
(0.018)\end{array}$ & $\begin{array}{l}-0.021 \\
(0.018)\end{array}$ \\
\hline Offshore & $\begin{array}{c}0.196^{* * *} \\
(0.009)\end{array}$ & $\begin{array}{c}0.158^{* * *} \\
(0.009)\end{array}$ & $\begin{array}{c}0.204^{* * *} \\
(0.009)\end{array}$ & $\begin{array}{c}0.163^{* * *} \\
(0.009)\end{array}$ \\
\hline $\ln \left(\right.$ Sales $\left._{f}\right)$ & $\begin{array}{c}0.008^{* * *} \\
(0.001)\end{array}$ & $\begin{array}{c}-0.018^{* * *} \\
(0.001)\end{array}$ & & \\
\hline $\ln \left(V A \operatorname{Prod}_{f}\right)$ & & & $\begin{array}{c}-0.005^{*} \\
(0.003)\end{array}$ & $\begin{array}{c}-0.018^{* * *} \\
(0.003)\end{array}$ \\
\hline $\ln \left(\right.$ Imports $\left._{f}\right)$ & & $\begin{array}{c}0.028^{* * *} \\
(0.001)\end{array}$ & & $\begin{array}{c}0.020^{* * *} \\
(0.001)\end{array}$ \\
\hline Industry Controls & yes & yes & yes & yes \\
\hline Adj.R2 & 0.08 & 0.11 & 0.08 & 0.10 \\
\hline $\mathrm{N}$ & 34,500 & 34,500 & 34,500 & 34,500 \\
\hline
\end{tabular}

Notes: Countries are low income if they are in the bottom two terciles of per-capita GDP. Industry controls are fixed effects for the firm's modal industry. Omitted category is firms with no CMS purchases. *, **, *** denote $10 \%, 5 \%$ and $1 \%$ significance respectively. $\mathrm{N}$ rounded for disclosure avoidance.

\footnotetext{
${ }^{28}$ I obtain countries' per-capita GDP in 2007 from the International Monetary Fund. The GDP data are unavailable for a small number of countries that represent less than one percent of imports in each CMS category.
} 


\section{$5.2 \quad$ Sourcing location decisions}

Having established the fact that offshoring firms source disproportionately more from low-wage locations, I estimate the differential impact of electronic network use by industry CAD and country human capital. To do so, I construct an indicator equal to one if a firm sources from a given country. The dataset therefore includes an observation for every potential firm-country import combination. I then estimate a triple interaction effect (similar to a difference-in-difference-in-difference estimator) of firm use of networks with its industry CAD intensity and country-level human capital. The estimating equation is given by

$$
\begin{gathered}
\operatorname{Pr}\left(y_{f j c}=1 \mid X\right)=\theta+F \beta_{F}+J \beta_{J}+C \beta_{c}+\beta_{\text {Dist } \text { Dist }_{f c}+\beta_{E * C A D}\left(\text { Enets }_{f} \times C A D_{j}\right)+} \\
\beta_{E * H C}\left(\text { Enets }_{f} \times H C_{c}\right)+\beta_{C A D * H C}\left(C A D_{j} \times H C_{c}\right)+\beta_{E * C A D * H C}\left(\text { Enets }_{f} \times C A D_{j} \times H C_{c}\right),
\end{gathered}
$$

where $y_{f, j, c}=1$ if firm $f$ in industry $j$ imports from country c. $F$ is a matrix of firm characteristics, $J$ is a matrix of industry characteristics, and $C$ is a matrix of country characteristics.

The firm variables, $F$, include the log of value-added labor productivity and electronic network use. The industry variables, $J$ include industry CAD intensity and the share of differentiated inputs in an industry. The latter is measured using the fraction of differentiated inputs in an industry from Nunn (2007). This variable controls for the possibility that CAD intensity may also reflect the extent to which an industry relies on differentiated inputs. ${ }^{29}$ The country variables, $C$, include country human capital and the relative foreign wage. The relative foreign wage is constructed from country-industryoccupation wages from the International Labor Organization and Oostendorp (2005). Additional details on all variables are in the online appendix. Dist $f_{c}$ is the log of distance between firm $f$ and country $c$. It is calculated using the great circle formula and is based on the latitudes and longitudes of each country's main city, as identified by CEPII, and the firm's closest manufacturing establishment. ${ }^{30}$ The remaining terms represent interaction terms between firm communication technology, industry CAD intensity, and country human capital.

\footnotetext{
${ }^{29}$ For multi-sector firms, industry variables are based on the employment-weighted average of their plants' industry CAD and differentiated input use. Note that the specification with firm fixed effects fully controls for all these factors, and well as any other firm or industry variation.

${ }^{30}$ The data are available here: www.cepii.fr/anglaisgraph/bdd/distances.htm.
} 
The main objective of this section is to assess how the relationship between firm technology and offshoring varies with country human capital. I therefore include country and/or firm fixed effects and focus on the interaction terms between these variables. This approach controls for all possible omitted country or firm (and industry) characteristics and is thus less susceptible to reverse causality and spurious correlation problems. I also include a specification with firm and country-by-industry fixed effects to ensure that the estimates are not driven by industry-level variation in production processes that might benefit from differences in country human capital. If country human capital does influence a firm's ability to use its technology to communicate about design specifications, then $\beta_{E * C A D * H C}$ should be positive across all specifications.

\subsection{Results}

Table 8 presents results from estimating equation (5.1) via OLS. I limit the analysis to firms with at least one offshoring establishment. To ensure that the data are not too sparse, I also include only those countries with at least ten importing firms. Column 1 reports estimates using country fixed effects. This specification allows for a quantification of the role of firm technology in the probability of sourcing from a given country, while controlling for all possible omitted factors that vary at the country level. The coefficient on the triple interaction between firm technology, industry CAD, and country human capital is positive and significant. This implies that the differential impact of electronic networks by industry CAD intensity is increasing in country human capital. ${ }^{31}$

Figure 6 plots the impact of firm use of networks by industry CAD intensity and country human capital. The left panel depicts the percentage point impact of electronic networks by country human capital for a low CAD industry (other apparel manufacturing), while the right panel depicts the impact for a high CAD industry (semi-conductor machinery manufacturing). The results are striking. Firm use of electronic communication in low CAD industries has close to a zero impact on the probability of sourcing from a country. In contrast, firm use of networks in high CAD industries decreases the likelihood of sourcing from low skill countries, while it increases the likelihood of sourcing from skill abundant countries. For example, relative to a firm not using networks, a firm using networks in semi-

\footnotetext{
${ }^{31}$ It is important to remember that country human capital may also affect production costs. This is likely reflected in the positive and significant interactions between industry CAD and country skill.
} 
Table 8: Offshore sourcing location selection

Dependent variable is 1 if firm $f$, in industry $j$, imports from country $c$

\begin{tabular}{|c|c|c|c|c|}
\hline & 1 & 2 & 3 & 4 \\
\hline Electronic networks $s_{f}$ & $\begin{array}{c}0.005 \\
(0.015)\end{array}$ & & & \\
\hline$\times C A D_{j}$ & $\begin{array}{c}-0.108^{* * *} \\
(0.029)\end{array}$ & & & \\
\hline$\times \ln \left(H C_{c}\right)$ & $\begin{array}{c}0.025 \\
(0.029)\end{array}$ & $\begin{array}{c}0.035 \\
(0.029)\end{array}$ & $\begin{array}{c}0.025 \\
(0.029)\end{array}$ & $\begin{array}{c}0.046 \\
(0.033)\end{array}$ \\
\hline$\times C A D_{j} \times \ln \left(H C_{c}\right)$ & $\begin{array}{c}0.229^{* * *} \\
(0.059)\end{array}$ & $\begin{array}{c}0.207^{* * *} \\
(0.059)\end{array}$ & $\begin{array}{c}0.230^{* * *} \\
(0.060)\end{array}$ & $\begin{array}{c}0.161^{* *} \\
(0.062)\end{array}$ \\
\hline$C A D_{j}$ & $\begin{array}{c}-0.079^{* * *} \\
(0.024)\end{array}$ & & & \\
\hline$\times \ln \left(H C_{c}\right)$ & $\begin{array}{c}0.115^{* * *} \\
(0.035)\end{array}$ & $\begin{array}{c}0.112^{* * *} \\
(0.040)\end{array}$ & $\begin{array}{c}0.118^{* * *} \\
(0.039)\end{array}$ & $\begin{array}{c}0.209 * * * \\
(0.074)\end{array}$ \\
\hline $\ln \left(\operatorname{VAProd}_{f}\right)$ & $\begin{array}{c}0.023^{* * *} \\
(0.004)\end{array}$ & & & \\
\hline $\ln \left(\right.$ Distance $\left._{f c}\right)$ & $\begin{array}{c}-0.265^{* * *} \\
(0.016)\end{array}$ & $\begin{array}{c}-0.022^{* * *} \\
(0.004)\end{array}$ & $\begin{array}{c}-0.053^{* * *} \\
(0.008)\end{array}$ & $\begin{array}{c}-0.048^{* * *} \\
(0.007)\end{array}$ \\
\hline $\ln \left(\right.$ Diff inputs $\left.s_{j}\right)$ & $\begin{array}{c}0.019 \\
(0.012)\end{array}$ & & & \\
\hline $\ln \left(w_{c} / w_{U S}\right)$ & & $\begin{array}{c}-0.013^{* * *} \\
(0.004)\end{array}$ & & \\
\hline $\ln \left(H C_{c}\right)$ & & $\begin{array}{c}0.126^{* * *} \\
(0.019)\end{array}$ & & \\
\hline Firm Fixed Effects & no & yes & yes & yes \\
\hline Country Fixed Effects & yes & no & yes & yes \\
\hline Industry-by-Country Fixed Effects & no & no & no & yes \\
\hline Adj. $R^{2}$ & 0.25 & 0.21 & 0.38 & 0.41 \\
\hline $\mathrm{N}$ & 134,100 & 100,400 & 134,500 & 134,500 \\
\hline
\end{tabular}

Notes: Sample is manufacturing firms with one or more offshoring establishments. Analysis is based on countries with at least 10 importers. CAD is the CAD/CAM intensity in a firm's industry. Diff Inputs is the fraction of inputs in an industry that are differentiated. $\mathrm{HC}$ is country human capital. Distance is the distance between a country's main city and the closest manufacturing establishment in the firm. $w_{c} / w_{U S}$ is the relative wage. Industry variables for multi-industry firms based on the employment-weighted average of the firms' industries. Industry indicators are the firm's modal industry. Standard errors clustered by industry. $*, * *, * * *$ denote $10 \%, 5 \%$ and $1 \%$ significance respectively. $\mathrm{N}$ rounded for disclosure avoidance.

conductor machinery manufacturing is 2.7 points less likely to source from a country with Guatemala's human capital, but over 11 points more likely to source from a country with the human capital 
Figure 5: Differential impact of country human capital on probability of sourcing from a country, by firm technology and industry CAD intensity
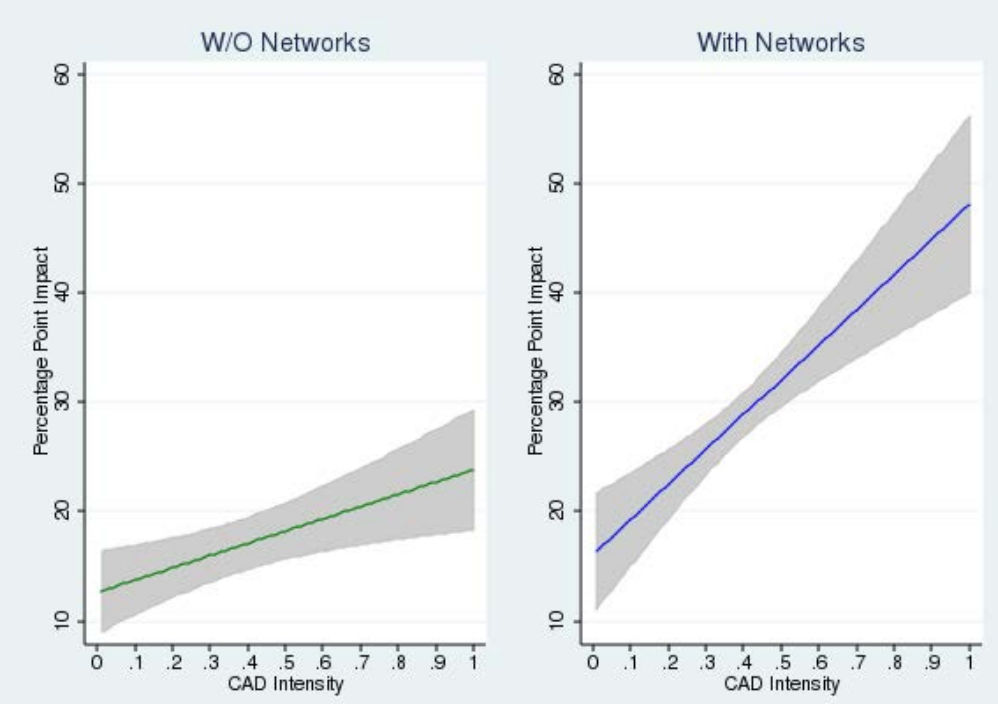

Notes: Figures depict the estimated effects of country human evaluated at different levels of industry CAD/CAM intensity. The left panel plots the effect for firms that do not use electronic networks, the right panel corresponds to firms using networks. Based on estimates with firm fixed effects reported in column 2 of Table 8.

equivalent of Mexico. For firms in industries in which it is feasible to use electronic communication to communicate about design and production specifications, country human capital is an important factor in the sourcing location decision.

Column 2 in Table 8 reports estimates of Equation (5.1) with firm fixed effects. Again, the estimated coefficient on $\beta_{E * C A D * H C}$ is positive and significant. Figure 5 plots the percentage point impact of country human capital on the probability that a given firm will source from that country as a function of the firm's technology and its industry CAD intensity. The left panel plots the estimated effect for firms that did not use electronic networks to control shipments and the right panel plots the effect for firms using networks. There is a significant difference in the effect of human capital across industry CAD intensity (positive slopes in both panels of figure 5), a difference in the effect of human capital depending upon firm use of networks (difference in level of estimated effect for a given value of industry CAD across panels), and a difference in the differential impact of networks by industry CAD intensity (difference in slopes across panels). Consider an increase in country human capital of about 15 percent, which is the amount necessary to bring Mexico up to Taiwan's level. For firms in 
Figure 6: Differential impact of firm technology on probability of sourcing from a country for low and high CAD industries, by country human capital
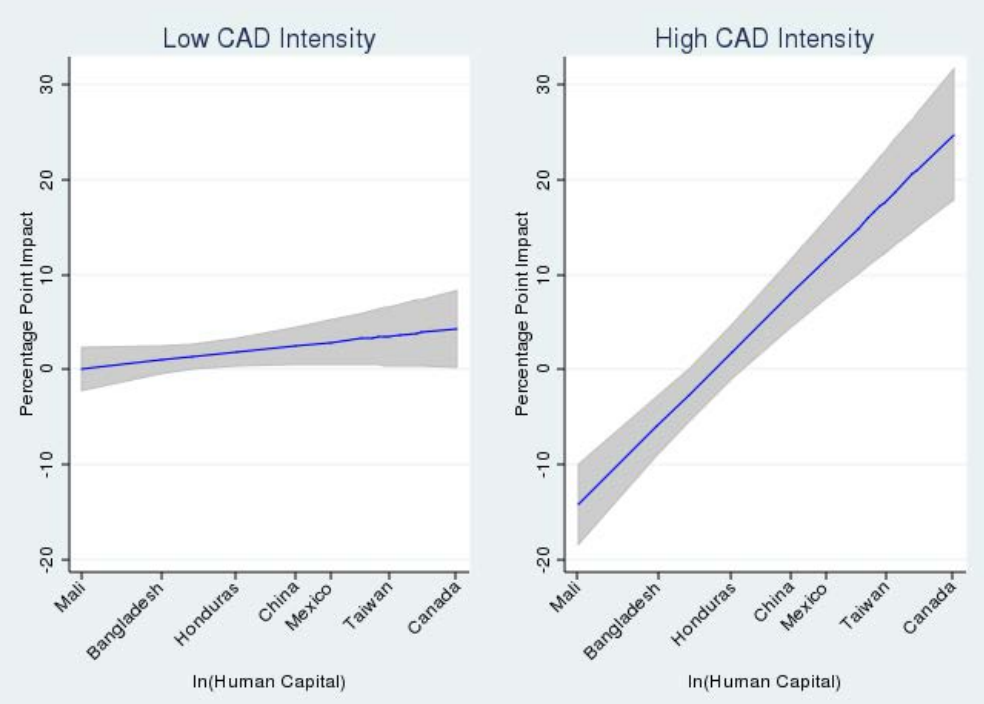

Notes: Figures depict estimated effects of firm use of electronic networks and industry CAD intensity by country human capital The left panel plots the effect for a low CAD/CAM intensity industry (other apparel manufacturing). The right panel corresponds to a high CAD/CAM industry (semi-conductor machinery manufacturing). Based on estimates with country fixed effects reported in column 1 of Table 8.

semi-conductor machinery manufacturing, this change implies a 7.8 percentage point increase from using networks on the probability of sourcing from a country. In contrast, the same change in human capital only implies a 2.9 point increase from using networks for firms in other apparel manufacturing.

The results presented in Table 8 also point to an important role for distance. The estimated coefficient on distance is negative and significant across all specifications. This indicates that a given firm is more likely to offshore to proximate countries, and that variation in the domestic distances for U.S. firms sourcing from the same foreign country is also an important factor in firms' global sourcing decisions.

\section{Conclusion}

Communication technology has revolutionized how individuals and firms interact across distances. This paper exploits novel micro-level data to provide some of the first evidence on how a firm's use of technology relates to its fragmentation of production across distinct geographic locations that are 
both foreign and domestic. Using difference-in-difference and first difference approaches, I find a strong and robust relationship between technology and fragmentation that is increasing in industry CAD intensity. Since CAD software is the predominant tool used to codify production designs and processes into an electronic format, these results provide new evidence consistent with the premise that firm technology facilitates fragmentation by lowering the costs associated with communicating production specifications across locations. The results are therefore suggestive of a close link between technology and fragmentation, although establishing a clear causal impact remains a challenge for future work.

This paper also documents the importance of domestic fragmentation of customized inputs in firms' global sourcing strategies. It is one of the first analyses to cover firms' domestic and foreign sourcing decisions, and shows that domestic fragmentation is far more prevalent than offshoring, both within and across manufacturing industries. Moreover, while the evidence supports the premise that technology lowers coordination costs, it also suggests that this effect is stronger for domestic rather than foreign fragmentation. Using linked firm-country data, I show that the positive differential impact of firm communication technology is present in high human capital countries, but not in the lower human capital countries to which U.S. firms tend to offshore their manufacturing production. The firm-country results also highlight the importance of within industry heterogeneity, not only in firm productivity differences, but also in firm use of technology in determining the countries to which firms offshore production.

The empirical evidence documented in this paper has three important implications for future work on fragmentation and offshoring. First, it highlights the fact that industry characteristics affect how communication technology affects firms' fragmentation decisions. Firms in certain industries are better able to exploit technology and/or have more to gain from its use. Second, it shows that higher technology firms and industries are more likely to source from high human capital countries. This result is consistent with the existence of complementarities between technology and skill (e.g., Bresnahan et al., 2002) and suggests that production fragmentation may be an additional channel through which skill-biased technical change affects the relative demand for skilled versus unskilled labor. Third, it suggests that the cost-lowering effect of communication technology (evident in the differential impact of electronic communication by industry CAD) is an increasing function of worker 
skill. This finding lends support to models that feature assortative matching at the firm level (Yeaple, 2005; Antràs et al., 2006; Sampson, 2014; Grossman et al., forth). It also underscores the importance of countries' factor endowments in shaping the patterns of trade and the types of firms that source from them. A challenge for future theory is to refine hierarchical predictions and aggregate gravity equations to account for these interactions. 


\section{A Appendix}

\section{A.1 Contract Manufacturing Questions}

The 2007 CMS purchase question is the third part of the special inquiries section, question 26 on the Census of Manufacturers (CM). The exact question is:

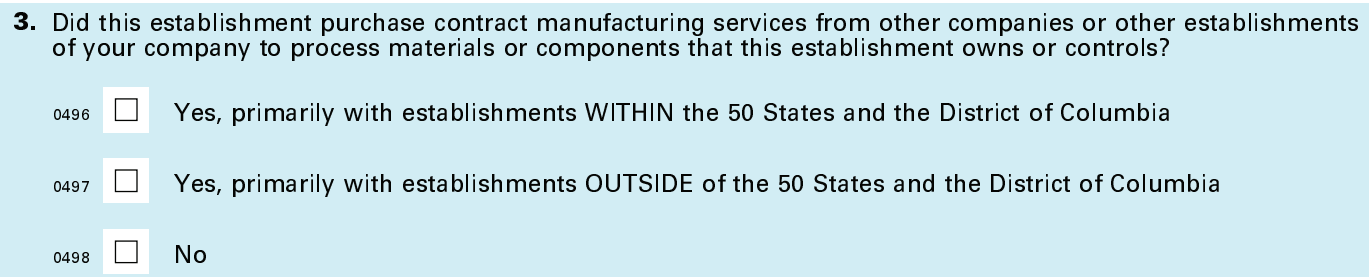

I cannot provide any actual examples of firms or contract manufacturing service (CMS) purchases in the Census data because the data are confidential and respondents' identities cannot be revealed. However, hypothetical examples of CMS purchases include the manufacturing of company A's MP-3 player components as instructed by company A; the assembly of company B's computer processing chips in B's overseas plants using specified inputs and a precise design criterion; and the production of company C's shoes in non-affiliated factories using soles provided and materials specified by company C. In each case, the purchaser furnishes production specifications to the manufacturing service provider.

The 2002 CMS purchase question is number B5 under question 28 on "Establishment Activities" in the 2002 CM. The exact question is: Did this establishment
5. Contract with another firm for any of your production using materials owned by this location? . . . . . . . . . . $8041 \square$ Yes $\quad 8042 \square$ No

A key difference between this question and the CMS question in 2007 is that this question only relates to contracting with another firm. For single unit firms, this distinction is irrelevant since any contracting must be outside the firm. I therefore use this question to construct a panel for single unit firms. Note that it is possible that this question will miss CMS purchases by firms in 2002 that controlled but did not own the input materials. This would constitute measurement error in the dependent variable which may attenuate results but should not bias them. 


\section{A.2 Description of the CMS sample}

The CM is conducted in years that end in 2 and 7 . It covers the universe of manufacturing establishments in the U.S, though not every establishment is asked the CMS question. While all large plants and all plants that belong to multi-unit firms were asked the CMS question, only a random sample of small and medium-sized plants was asked the question. Data for the smallest manufacturing plants, generally those with less than five employees, are based only on administrative records and therefore do not include any information about those plants' CMS purchases. ${ }^{32}$ Since the administrative records are often based on imputed data, have no information about CMS purchases, and account for only $1.5 \%$ of sales and three percent of employment in the manufacturing sector, I exclude them from the entire analysis. All establishments that receive a census form in the mail are legally required to return the completed form. Despite the legal requirement, a fraction of establishments did not respond to the CMS question.

I assess the observable characteristics of plants outside the CMS sample to address potential issues from sample selection. While the CMS sample covers 54 percent of manufacturing establishments (excluding the administrative records), it includes 75 percent of sales and 71 percent of employment. Table A.1 presents information on plants in the CMS sample relative to those outside the sample. The first three columns provide participation shares and show that while the CMS sample comprises of 54 percent of U.S. manufacturing establishments (excluding administrative records), it covers 75 percent of sales and 71 percent of employment. The last three columns of Table A.1 present summary statistics by CMS non-response type. As expected, establishments not asked the CMS question are substantially smaller than plants in the sample. To address potential selection bias in the analyses, I use a number of establishment-level variables, including sales, employment, age, firm age, multi-unit firm status, industry, and industry employment interactions, to estimate, via logit, the probability that an establishment will be in the CMS sample. I then predict the probability that an observation is in the sample and, following Cameron and Trivedi (2005), use the inverse probability as a weight in the summary statistics. ${ }^{33}$

\footnotetext{
${ }^{32}$ The CM uses both short and long form questionnaires, and only the long forms ask the CMS purchase questions. While all large and multi-unit firm establishments receive the long form, only a random sample of small, single-unit firms receive the long form. Data for the smallest establishments is imputed from Federal tax returns and industry averages.

${ }^{33}$ Cameron and Trivedi recommend using weights ("that are inversely proportional to the probability of inclusion in
} 


\section{A.3 Nested Logit Estimates}

In this section, I show that the main results in the paper hold when estimating the probability of fragmentation and offshoring via nested logit. Figure A.1 illustrates the nesting structure. Following the discrete choice literature, I assume that a plant's latent profit function is a linear function of plant and fragmentation location characteristics, and furthermore additively separable into a component that varies only with the decision to fragment and a component that reflects the profits derived from fragmenting domestically or offshore. Under these assumptions, the latent profit function for plant $i$ can be written as

$$
U_{i f s}=z_{i f}^{\prime} \alpha+w_{i f s}^{\prime} \beta+\varepsilon_{i f s}
$$

where $f$ denotes the level one decision to fragment or not and $s$ denotes the plant's level two fragmentation choice within each nest. ${ }^{34}$ If the distribution of $\varepsilon_{i f s}$ is given by a multivariate extreme value with parameter $\lambda$, then the probability that plant $i$ chooses sourcing alternative $s$ in nest $f$ is given by:

$$
\begin{aligned}
P_{i f s} & =P_{i f} \times P_{i s \mid f} \\
& =\frac{e^{z_{i f}^{\prime} \alpha+\lambda_{f} I_{i f}}}{\sum_{l=1}^{2} e^{z_{i f}^{\prime} \alpha+\lambda_{l} I_{i l}}} \times \frac{e^{w_{i f s}^{\prime} \beta / \lambda_{f}}}{\sum_{m \in f} e^{w_{i m s}^{\prime} \beta / \lambda_{f}}}
\end{aligned}
$$

where $I_{i f} \equiv \ln \left(\sum_{m \in f} e^{w_{i f s}^{\prime} \beta / \lambda_{f}}\right)$ is the inclusive value for nest $f$.

Since the majority of variables available for the analysis are case-specific, for estimation purposes, it is useful to re-write equation A.1, distinguishing between the case and alternative-specific variables.

$$
U_{i f s}=z_{i}^{\prime} \alpha_{f}+\beta_{\text {dist }} \text { dist }_{i f s}+x_{i}^{\prime} \beta_{f s}+\varepsilon_{i f s} .
$$

From the model, $z$ includes a plant's local labor costs, dist $t_{\text {ifs }}$ is a measure of distance between a

the sample") for a descriptive or data summary approach. They note that if a regression model is correctly specified then sample weighted and unweighted estimates should have the same probability limit, Cameron and Trivedi (2005) pp. 817-21. In early versions of the paper, I verified that the estimated regression coefficients were quite similar regardless of weighting.

${ }^{34}$ The no fragmentation nest is degenerate since plants that do not fragment production have no additional decision to make. To achieve identification in the estimation process, I therefore set the dissimilarity parameter to one for this nest. 
plant and each fragmentation alternative, and $x$ is a vector that includes plant-level productivity and communication technology.

\section{A.3.1 Results from the nested logit model}

Table A.2 presents the coefficients from estimating equation A.2. Column 1 presents the baseline results. Since the wage measure only varies by state, the standard errors are clustered at this level. Clustering by industry does not change the statistical significance of the coefficients. All coefficients have the expected sign and are statistically significant. As is well known, the coefficients from a nonlinear model must be transformed in order to assess their marginal effects. Table A.3 in the online appendix provides the average marginal effects (AMEs) and their standard deviations for the main variables of interest. I do not calculate a statistical significance for each effect and instead rely on the standard errors reported in Table A.2 which Greene (2010) argues are both a sufficient and more informative metric. Panel A presents results from a specification without the CAD interaction. The estimates suggest that on average, a plant using communication technology is 10 percentage points more likely to fragment production. Technology increases the probability of domestic sourcing by 9 points and offshoring by 1 point. These effects represent a 30 and 50 percent increase over the mean share of fragmentation and offshoring respectively.

Panel B presents results from a specification with the CAD interaction. Estimates on interaction terms are difficult to assess in non-linear models. Ai and Norton (2003) show that even the sign on the estimated coefficient is not necessarily the sign of the marginal effect. In more recent work, Greene (2010) argues that figures provide the most informative economic interpretation of the marginal effects of interaction terms in non-linear models. Following this approach, Figure A.2 plots the AMEs of electronic communication by industry CAD intensity for the probability of each outcome. Panel (a) shows that plants using electronic networks are less likely not to fragment, and that this is particularly true for plants in CAD-intensive industries. Panel (b) depicts a positive relationship between electronic network use and the probability of domestic fragmentation that is almost twice the size for plants in the most CAD-intensive industries relative to those in the least CAD-intensive industries. In contrast, panel (c) suggests that this mechanism is not present for fragmentation offshore. While use of electronic networks does have a positive relationship with the probability most plants will offshore, 
its impact is decreasing in CAD intensity and is essentially zero for plants in the most CAD-intensive industries. Panel (d) highlights the differential impact across industries showing that the conditional probability of offshoring is strongly decreasing in CAD intensity. These results are all consistent with the OLS estimates presented in the paper. Plant communication technology increases the likelihood of fragmentation more in industries in which the production process is easier to translate into an electronic format, but there is no evidence that this mechanism increases foreign sourcing relative to domestic sourcing.

Table A.3 in the online appendix also presents the average marginal effects for distance and wages. The negative coefficient for distance, the only alternative-specific regressor, implies that increasing the distance between a plant and a potential sourcing location decreases the probability that the plant will source from that location. The remaining variables are all case-specific, so their coefficients are interpreted relative to the omitted category, as in a multinomial logit model. Doubling the state wage is associated with a 15.6 point increase in the probability of fragmentation. The probability of fragmentation is also increasing in productivity.

The estimated wage coefficient will be biased if state-level wages are correlated with differences in worker skill or local demand and these factors affect fragmentation. Another potential issue is that a high concentration of manufacturing employment in a state may lead to both more fragmentation and to higher wages. Columns 3-5 show that the estimated coefficients and their statistical significance are all robust to controlling for i) state-level skill differences, measured using the American Community Survey data as the share of workers with a college degree; ii) variation in local demand, measured as personal income in a plant's local market from the Bureau of Economic Analysis; and iii) manufacturing concentration, measured as the share of manufacturing employment to population in a state. ${ }^{35}$ Column 6 addresses the possibility that location may be endogenous to a plant's fragmentation strategy, which could bias estimates on the effect of distance, by using the subset of plants that have existed in the same physical location for at least ten years. Once again, the coefficients and their significance are largely unchanged. The dissimilarity parameter for the fragmentation nest, $\lambda_{F}$, is about 0.2 in all specifications. This estimate is statistically different from one, confirming that IIA is violated within

\footnotetext{
${ }^{35}$ I have also used measures of MSP concentration near the plant. While this does affect the estimate on the distance to the closest MSP, the wage coefficient is robust. These results are available upon request.
} 
the fragmentation nest and that a NLM is therefore appropriate.

\section{A.4 IV Estimation}

As an alternative way to address the potential for reverse causality between technology and fragmentation and productivity and fragmentation, I employ an instrumental variable (IV) approach. An IV is also useful here since the electronic network indicator is a proxy variable and therefore subject to measurement error. I implement the IV using each plant's 2002 use of electronic networks and 2002 productivity as instruments. The share of plants using networks to control or coordinate shipments in 2002 is roughly half the 2007 share for each CMS category. For the lagged instrument to be valid, plants' use of networks in 2002 must be determined by factors other than their decision to fragment production in 2007 and entail a sunk cost. The instrument can identify a causal relationship if plants that used networks in 2002 to facilitate sales decide to fragment in 2007 because their existing communication technology made fragmentation relatively more profitable, for example by lowering coordination costs.

There are three reasons to believe that factors other than fragmentation play a role in plants' use of networks to coordinate shipments: 1) almost half of the plants that used networks to coordinate shipments in 1999 did not use networks to purchase inputs (DOC, 2001); 2) McElheran (2015) finds that, although E-buying and E-selling share the same technology platforms, E-selling generally entails more complex organizational changes and entails a sunk costs; and 3) in 2007, one third of plants that did not fragment production used electronic networks to coordinate shipments. The instrument's power to identify a causal relationship also depends upon the existence of plants that used networks in 2002 but did not fragment production. Although the 2002 CM did not ask the same 2007 CMS purchase question, it did ask whether a plant purchased CMS from another firm. This question allows me to identify, for all single-unit firms, whether or not the firm purchased CMS in $2002 .{ }^{36}$ I therefore run the IV on the subset of single-unit firms that did not fragment in 2002. For this sub-sample, plants' 2002 technology status and productivity are not a function of their fragmentation status.

IV estimates on the subset of potential Adopters (columns 3 and 6) show that selection is an impor-

\footnotetext{
${ }^{36} \mathrm{~A}$ single unit firm that fragments production must do so by contracting with another firm. A plant that belongs to a multi-unit firm could purchase CMS from another plant in the firm. This analysis also shows that the results are not driven by differences between intra-firm and outsourced fragmentation.
} 
tant factor in plants' fragmentation strategies. These estimates exploit variation in 2002 productivity for plants that did not fragment in 2002. Of the plants that did not fragment in 2002, those in the top productivity tercile are 6.1 points more likely to fragment in 2007 . The right panel shows that fragmenting plants in the top productivity tercile are about five points more likely to source offshore. These results extend existing evidence by showing that selection is an important factor in the relationship between productivity and firms' sourcing strategies. Productivity prior to fragmentation and offshoring is an important predictor of firms' sourcing strategies. First stage regressions are presented in Appendix Table A.5. The lagged instrument is always significant in its own first stage regression, with the expected positive coefficient. In addition, the F-statistics for the null hypothesis that the instruments are jointly equal to zero are well above the threshold of 10 proposed in Stock et al. (2002).

IV estimates that instrument for use of networks in 2007 with network use in 2002 are larger than the OLS estimates, which is consistent with measurement error from using plants' use of networks to coordinate shipments as a proxy variable for whether electronic communication is integrated into the production process. The IV strategy is identified by variation in plants' use of networks that is driven by factors other than fragmentation. The "Adopters" column in each panel therefore shows that the IV estimates are robust when the sample is limited to plants that did not fragment production in 2002.

\section{References}

Acemoglu, Daron, Philippe Aghion, Claire Lelarge, John Van Reenen, and Fabrizzio Zilibotti, "Technology, Information and the Decentralization of the Firm," Quarterly Journal Economics, 2007, 122, 1759-1799.

_ , _, Rachel Griffith, and Fabrizzio Zilibotti, "Vertical Integration and Technology: Theory and Evidence," Journal of the European Economic Association, 2010, 8, 989-1033.

Ai, Chunrong and Ed Norton, "Interaction terms in logit and probit models," Economic Letters, 2003, 80, 123-129.

Akerman, Anders and Loriane Py, "Outsourcing and the Division of Labor between Firms: Evidence from Swedish Cities," mimeo, Stockholm University September 2011.

Antràs, Pol, Luis Garicano, and Esteban Rossi-Hansberg, "Offshoring in a Knowledge Economy," Quarterly Journal of Economics, 2006, 121 (1). 
_ , _ , and _ , "Organizing Offshoring: Middle Managers and Communication Costs," in Elhanan Helpman, Dalia Marin, and Thierry Verdier, eds., The Organization of Firms in a Global Economy, Harvard University Press, 2008, pp. 311-339.

Baker, George and Thomas Hubbard, "Make versus Buy in Trucking: Asset Ownership, Job Design, and Information," The American Economic Review, 2003, 93, 551-572.

- and Thomas N. Hubbard, "Contractibility and Assest Ownership: On-Board Computers and Governance in U.S. Trucking," Quarterly Journal of Economics, 2004, pp. 1443-1479.

Barro, Robert J. and Jong-Wha Lee, "International Data on Educational Attainment: Updates and Implications," CID Working Paper 042 April 2000.

Bernard, Andrew B., J. Bradford Jensen, and Peter K. Schott, "Importers, Exporters, and Multinationals: A Portrait of Firms in the U.S. that Trade Goods," in J. Bradford Jensen and Peter K. Schott, eds., Producer dynamics: New Evidence from Micro Data, University of Chicago Press, 2009.

Bloom, Nicholas, Luis Garicano, Raffaella Sadun, and John Van Reenen, "The distinct effects of Information Technology and Communication Technology on firm's organization," mimeo, Stanford University August 2011.

_, Mirko Draca, and John Van Reenen, "Trade Induced Technical Change: The Impact of Chinese Imports on Innovation, Diffusion, and Productivity," Review of Economic Studies, 2016, 83, $87-117$.

Boler, Esther Ann, Andreas Moxnes, and Karen Helene Ulltveit-Moe, "R\&D, International Sourcing and the Joint Impact on Firm Perform," American Economic Review, 2015, 105, 37043739 .

Bresnahan, Timothy F., Erik Brynjofsson, and Lorin M. Hitt, "Information Technology, Workplace Organization, and the Demand for Skilled Labor: Firm-Level Evidence," Quarterly Journal Economics, 2002, 117, 339-376.

Brynjofsson, Erik and Lorin M. Hitt, "Beyond Computation: Information Technology, Organizational Transformation and Business Performance," Journal of Economic Perspectives, 2000, 14, $23-48$.

Bustos, Paula, "Trade Liberalization, Exports and Technology Upgrading: Evidence on the Impact of MERCOSUR on Argentinian Firms," American Economic Review, 2011, 101 (1), 304-340.

Cameron, A. Colin and Pravin K. Trivedi, Microeconometrics Methods and Applications, Cambridge University Press, 2005.

Campa, José and Linda S. Goldberg, "The Evolving External Orientation of Manufacturing: A Profile of Four Countries," Federal Reserve Bank of New York Economic Policy Review, 1997, 3 (3), 53-81.

Costinot, Arnaud, Jonathan Vogel, and Su Wang, "An Elementary Theory of Global Supply Chains," Review of Economic Studies, 2013, 80, 109-144. 
_ , Lindsay Oldenski, and James Rauch, "Adaptation and the Boundary of Multinational Firms," Review of Economics and Statistics, 2011, 93 (1), 298-308.

Crespi, Gustavo, Chiara Criscuolo, and Jonathan E. Haskel, "Information Technology, Organisational Change and Productivity," Discussion Paper 6105, C.E.P.R. 2007.

Deardorff, Alan V., "Fragmentation in simple trade models," North American Economic Journal of Economics and Finance, 2001, 12, 121-137.

DOC, "U.S. Department of Commerce E-Stats Report," Technical Report, Economics and Statistics Administration 2001.

Fally, Thibault, "Production Staging: Measurement and Facts," Working Paper, University of Colorado-Boulder October 2012.

Feinberg, Susan E. and Michael P. Keane, "Accounting for the Growth of MNC-Based Trade Using a Structural Model of U.S. MNCs," The American Economic Review, December 2006, 96 (5), $1515-1558$.

Greene, William, "Testing hypotheses about interaction terms in nonlinear models," Economic Letters, 2010, 107, 291-296.

Grossman, Gene M. and Esteban Rossi-Hansberg, "Trading Tasks: A Simple Theory of Offshoring," The American Economic Review, 2008, 98 (5), 1978-1997.

_ , Elhanan Helpman, and Philipp Kircher, "Matching and Sorting in a Global Economy," Journal of Political Economy, forth.

Grossman, Sanford J. and Oliver D. Hart, "The Costs and Benefits of Ownership: A Theory of Vertical and Lateral Integration," Journal of Political Economy, August 1986, 94, 691-719.

Hall, Robert E. and Charles I. Jones, "Why Do Some Countries Produce So Much More Output Per Worker Than Others?," Quarterly Journal of Economics, 1999, pp. 83-116.

Handwerker, Elizabeth Weber and James R. Spletzer, "What Can OES Data Tell Us About Growing Wage Inequality," mimeo 2010.

Helpman, Elhanan, Marc Melitz, and Yona Rubinstein, "Estimating Trade Flows: Trading Partners and Trading Volumes," Quarterly Review of Economics, 2008, 123, 441-487.

Hillberry, Russell and David Hummels, "Trade responses to geographic frictions: A decomposition using micro-data," European Economic Review, 2008, 52, 527-550.

Holmes, Thomas J. and John J. Stevens, "Exports, Borders, Distance, and Plant Size," Journal of International Economics, 2012, 88, 91-103.

Hummels, David, Jun Ishii, and Kei-Mu Yi, "The Nature and Growth of Vertical Specialization in World Trade," Journal of International Economics, 2001, 54 (1), 75-96.

Johnson, Robert and Guillermo Noguera, "Fragmentation and Trade in Value Added Over Four Decades," Working Paper 18186, NBER 2012. 
Jones, Ronald W. and Henryk Kierzkowski, "Globalization and the Consequences of International Fragmentation," in R. Dornbusch, G. Calvo, and M. Obstfeld, eds., Money, Factor Mobility, and Trade: Essays in Honor of Robert A. Mundell, MIT Press, 2001.

Kee, Hiau Looi and Heiwei Tang, "Domestic Value Added in Exports: Theory and Firm Evidence from China," American Economic Review, 2016, 106 (6), 1402-36.

Kohler, Willhelm, "Aspects of International Fragmentation," Review of International Economics, 2004, 12 (5), 793-816.

Kohler, Willhelm K. and Marcel Smolka, "Sourcing Premia with Incomplete Contracts: Theory and Evidence," The B.E. Journal of Economic Analysis and Policy: Contributions, 2011, 11 (1).

Lileeva, Alla and Daniel Trefler, "Improved Access to Foreign Markets Raises Plant-Level Productivity...For Some Plants," Quarterly Journal of Economics, August 2010, 125 (3), 1051-1099.

McElheran, Kristina S., "Do Market Leaders Lead in Business Process Innovations? The Case(s) of E-Business Adoption," Management Science, 2015, 61, 1197-1216.

Melitz, Marc and J Constantini, "The Dynamics of Firm-Level Adjustment to Trade Liberalization," in Elhanan Helpman, Dalia Marin, and Thierry Verdier, eds., The Organization of Firms in a Global Economy, Harvard University Press, 2008.

Nunn, Nathan, "Relationship-Specificity, Incomplete Contracts and the Pattern of Trade," Quarterly Journal of Economics, May 2007, 122 (2), 569-600.

Oostendorp, Remco H., "The Standardized ILO October Inquiry 1983-2003," mimeo, Amsterdam Institute for International Development 2005.

Rajan, Raghuram G. and Luigi Zingales, "Financial Dependence and Growth," The American Economic Review, June 1998, 88 (3), 559-586.

Sampson, Thomas, "Selection into Trade and Wage Inequality," American Economic Journal: Microeconomics, 2014, 6, 157-202.

Schott, Peter K., "Across-Product Versus Within-Product Specialization in International Trade," Quarterly Journal Economics, 2004, 119 (2), 647-678.

StataCorp, Stata 14 Base Reference Manual, Stata Press, 2015.

Stock, James H., Jonathan H. Wright, and Motohiro Yogo, "A Survey of Weak Instruments and Weak Identification in Generalized Method of Moments," Journal of Business and Economic Statistics, 2002, 20, 518-529.

Tomiura, Eiichi, "Foreign outsourcing, exporting, and FDI: A productivity comparison at the firm level," Journal of International Economics, 2007, 72, 113-127.

Yeaple, Stephen Ross, "The Role of Skill Endowments in the Structure of U.S. Outward Foreign Direct Investment," The Review of Economics and Statistics, 2003, 85 (3), 726-734.

_ , "A Simple Model of Firm Heterogeneity, International Trade, and Wages," Journal of International Economics, 2005, 65 (1), 1-20. 
_ , "Firm heterogeneity and the structure of U.S. multinational activity," Journal of International Economics, 2009, 78, 206-215. 


\section{Appendix Figures and Tables}

Figure A.1: Nested logit structure

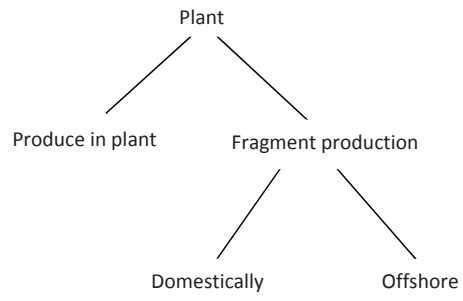

Figure A.2: Average marginal effects of electronic networks, by industry CAD intensity

(a) No Fragmentation

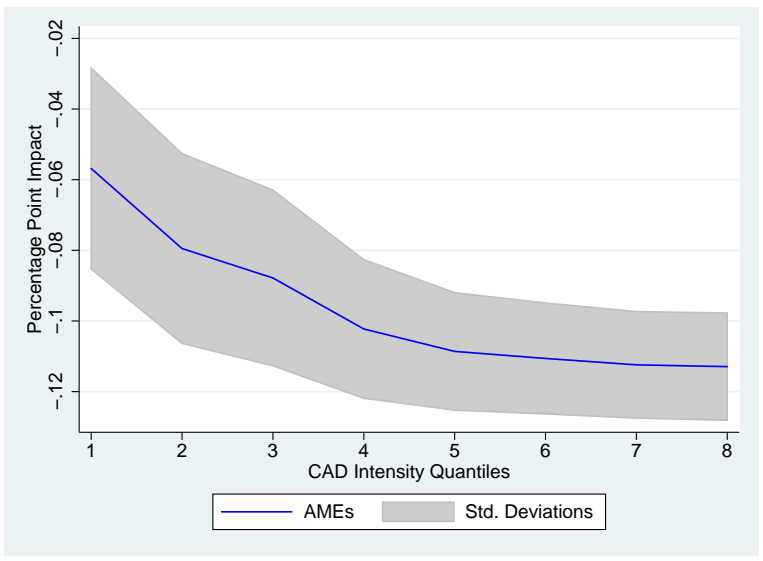

(c) Offshoring

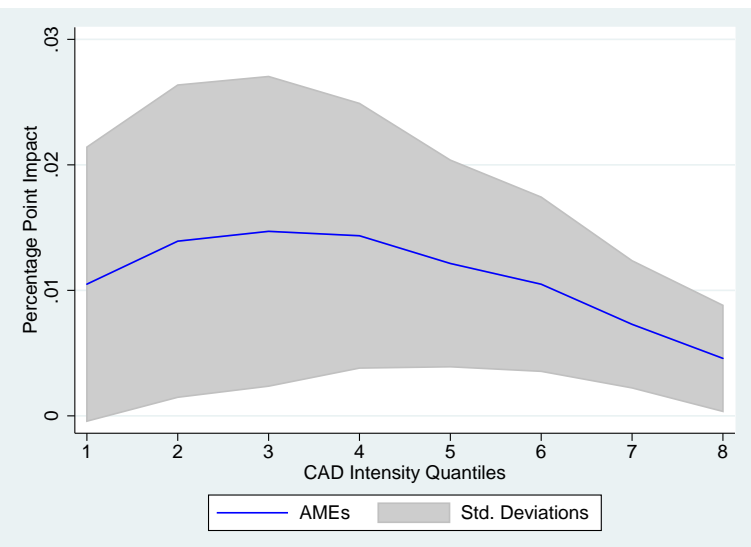

(b) Domestic Fragmentation

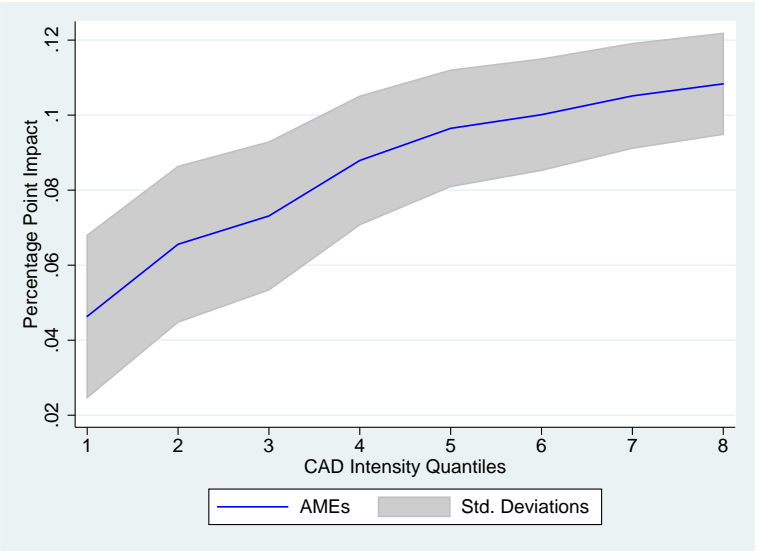

(d) Offshoring | Fragmentation

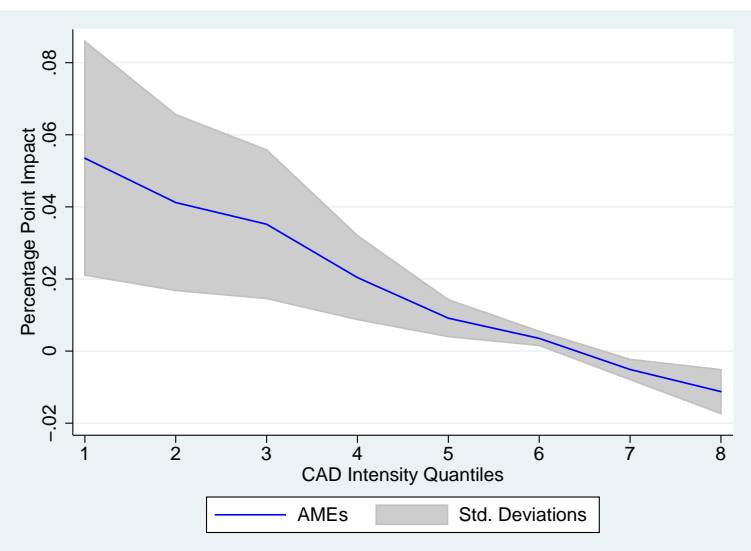

Notes: Average marginal effects of plant use of electronic networks evaluated at different levels of industry CAD/CAM intensity. Based on the estimates reported in column 2 of Table A.2. 
Table A.1: Plant characteristics by response status

\begin{tabular}{|c|c|c|c|c|c|c|}
\hline & \multicolumn{3}{|c|}{ Participation Shares } & \multicolumn{3}{|c|}{ Means } \\
\hline & Plants & Sales & Emp & Sales $^{a}$ & Emp & $\ln (\mathrm{VAP})$ \\
\hline In CMS Sample & 0.54 & 0.75 & 0.71 & 36,778 & 86 & 4.56 \\
\hline \multicolumn{7}{|c|}{ Out of CMS Sample } \\
\hline Not Answered & 0.21 & 0.23 & 0.24 & 29,548 & 77 & 4.61 \\
\hline Not Asked & 0.25 & 0.02 & 0.05 & 2,314 & 13 & 4.25 \\
\hline No Info & 0.00 & 0.00 & 0.00 & 21,147 & 61 & 4.75 \\
\hline All Manufactures & 1.00 & 1.00 & 1.00 & 26,638 & 66 & 4.50 \\
\hline
\end{tabular}

Notes: Approximately 196,800 manufacturing plants; excludes administrative records. ${ }^{a}$ Sales in $\$ 000$ s. 
Table A.2: Nested Logit Estimation Results

Dependent variable denotes plant $i$, in industry $j$ and state $h$, fragmentation status, $s$

\begin{tabular}{|c|c|c|c|c|c|c|}
\hline & Baseline & $\mathrm{W} / \mathrm{CAD}$ & Demand & Skill & Manuf & $10+$ Yrs. \\
\hline $\ln \left(\right.$ Distance $\left._{i s}\right)$ & $\begin{array}{c}-0.063^{* * *} \\
(0.006)\end{array}$ & $\begin{array}{c}-0.035^{* * *} \\
(0.008)\end{array}$ & $\begin{array}{c}-0.033^{* * *} \\
(0.007)\end{array}$ & $\begin{array}{c}-0.033^{* * *} \\
(0.008)\end{array}$ & $\begin{array}{c}-0.038^{* * *} \\
(0.008)\end{array}$ & $\begin{array}{c}-0.025^{* * *} \\
(0.009)\end{array}$ \\
\hline \multicolumn{7}{|l|}{ Level 1: Fragment } \\
\hline $\ln \left(\right.$ wage $\left._{h}\right)$ & $\begin{array}{c}0.823^{* * *} \\
(0.121)\end{array}$ & $\begin{array}{c}1.182^{* * *} \\
(0.165)\end{array}$ & $\begin{array}{c}1.159^{* * *} \\
(0.163)\end{array}$ & $\begin{array}{c}1.088^{* * * *} \\
(0.165)\end{array}$ & $\begin{array}{c}1.080^{* * *} \\
(0.183)\end{array}$ & $\begin{array}{c}1.227^{* * *} \\
(0.148)\end{array}$ \\
\hline $\ln (B E A$ Income $)$ & & & $\begin{array}{c}0.008 \\
(0.009)\end{array}$ & & & \\
\hline $\ln \left(\right.$ Share college $\left._{h}\right)$ & & & & $\begin{array}{c}0.126 \\
(0.089)\end{array}$ & & \\
\hline $\ln \left(\right.$ Share manuf $\left._{h}\right)$ & & & & & $\begin{array}{c}0.078^{* *} \\
(0.037)\end{array}$ & \\
\hline $\begin{array}{l}\text { NAICS } 4 \text { controls } \\
\text { Level 2: Domestic }\end{array}$ & yes & yes & yes & yes & yes & yes \\
\hline Elec. networks $s_{i}$ & $\begin{array}{c}0.524^{* * *} \\
(0.014)\end{array}$ & $\begin{array}{c}0.492^{* * *} \\
(0.028)\end{array}$ & $\begin{array}{c}0.493^{* * *} \\
(0.028)\end{array}$ & $\begin{array}{c}0.493^{* * *} \\
(0.027)\end{array}$ & $\begin{array}{c}0.489^{* * *} \\
(0.028)\end{array}$ & $\begin{array}{c}0.502^{* * *} \\
(0.033)\end{array}$ \\
\hline$\times \ln \left(C A D_{j}\right)$ & & $\begin{array}{l}-0.029 \\
(0.029)\end{array}$ & $\begin{array}{l}-0.029 \\
(0.028)\end{array}$ & $\begin{array}{l}-0.029 \\
(0.028)\end{array}$ & $\begin{array}{l}-0.029 \\
(0.029)\end{array}$ & $\begin{array}{l}-0.011 \\
(0.030)\end{array}$ \\
\hline $\ln \left(\right.$ VAProd $\left._{i}\right)$ & $\begin{array}{c}0.211^{* * *} \\
(0.012)\end{array}$ & $\begin{array}{l}0.212^{* * *} \\
(0.012)\end{array}$ & $\begin{array}{c}0.211^{* * *} \\
(0.012)\end{array}$ & $\begin{array}{c}0.212^{* * * *} \\
(0.012)\end{array}$ & $\begin{array}{c}0.212^{* * *} \\
(0.012)\end{array}$ & $\begin{array}{c}0.230^{* * *} \\
(0.016)\end{array}$ \\
\hline $\ln \left(\right.$ Diff inputs $\left.s_{j}\right)$ & $\begin{array}{c}0.266^{* * *} \\
(0.045)\end{array}$ & $\begin{array}{c}0.257^{* * *} \\
(0.046)\end{array}$ & $\begin{array}{c}0.257^{* * *} \\
(0.046)\end{array}$ & $\begin{array}{c}0.257^{* * *} \\
(0.046)\end{array}$ & $\begin{array}{c}0.256^{* * * *} \\
(0.046)\end{array}$ & $\begin{array}{c}0.252^{* * *} \\
(0.052)\end{array}$ \\
\hline $\ln \left(C A D_{j}\right)$ & & $\begin{array}{c}1.141^{* * *} \\
(0.290)\end{array}$ & $\begin{array}{c}1.232^{* * *} \\
(0.291)\end{array}$ & $\begin{array}{c}1.008^{* * * *} \\
(0.300)\end{array}$ & $\begin{array}{l}0.854^{* *} \\
(0.352)\end{array}$ & $\begin{array}{c}1.452^{* * *} \\
(0.293)\end{array}$ \\
\hline \multicolumn{7}{|l|}{ Level 2: Offshore } \\
\hline Elec. networks $s_{i}$ & $\begin{array}{c}0.538^{* * *} \\
(0.017)\end{array}$ & $\begin{array}{c}0.431^{* * *} \\
(0.030)\end{array}$ & $\begin{array}{c}0.435^{* * *} \\
(0.030)\end{array}$ & $\begin{array}{c}0.435^{* * *} \\
(0.029)\end{array}$ & $\begin{array}{c}0.423^{* * *} \\
(0.029)\end{array}$ & $\begin{array}{c}0.458^{* * * *} \\
(0.033)\end{array}$ \\
\hline$\times \ln \left(C A D_{j}\right)$ & & $\begin{array}{c}-0.132^{* * *} \\
(0.036)\end{array}$ & $\begin{array}{c}-0.126^{* * *} \\
(0.036)\end{array}$ & $\begin{array}{c}-0.126^{* * *} \\
(0.035)\end{array}$ & $\begin{array}{c}-0.138^{* * *} \\
(0.036)\end{array}$ & $\begin{array}{c}-0.082^{* *} \\
(0.036)\end{array}$ \\
\hline $\ln \left(\right.$ VAProd $\left._{i}\right)$ & $\begin{array}{c}0.247^{* * *} \\
(0.015)\end{array}$ & $\begin{array}{c}0.241^{* * *} \\
(0.016)\end{array}$ & $\begin{array}{c}0.239^{* * *} \\
(0.016)\end{array}$ & $\begin{array}{c}0.239^{* * * *} \\
(0.016)\end{array}$ & $\begin{array}{c}0.243^{* * *} \\
(0.016)\end{array}$ & $\begin{array}{c}0.253^{* * *} \\
(0.019)\end{array}$ \\
\hline $\ln \left(\right.$ Diff $\left._{\text {inputs }}\right)$ & $\begin{array}{c}0.580^{* * * *} \\
(0.072)\end{array}$ & $\begin{array}{c}0.420 * * * \\
(0.072)\end{array}$ & $\begin{array}{c}0.410^{* * *} \\
(0.069)\end{array}$ & $\begin{array}{c}0.410^{* * *} \\
(0.070)\end{array}$ & $\begin{array}{c}0.431^{* * * *} \\
(0.073)\end{array}$ & $\begin{array}{c}0.382^{* * *} \\
(0.077)\end{array}$ \\
\hline $\ln \left(C A D_{j}\right)$ & & $\begin{array}{c}1.248^{* * *} \\
(0.274)\end{array}$ & $\begin{array}{c}1.331^{* * *} \\
(0.276)\end{array}$ & $\begin{array}{c}1.108^{* * *} \\
(0.284)\end{array}$ & $\begin{array}{c}0.968^{* * *} \\
(0.338)\end{array}$ & $\begin{array}{c}1.521^{* * *} \\
(0.275)\end{array}$ \\
\hline$\lambda_{F}$ & $\begin{array}{c}0.182^{* * *} \\
(0.021)\end{array}$ & $\begin{array}{c}0.132^{* * *} \\
(0.031)\end{array}$ & $\begin{array}{c}0.124^{* * *} \\
(0.029)\end{array}$ & $\begin{array}{c}0.124^{* * *} \\
(0.030)\end{array}$ & $\begin{array}{c}0.142^{* * *} \\
(0.030)\end{array}$ & $\begin{array}{c}0.096^{* * *} \\
(0.034)\end{array}$ \\
\hline Log Likelihood & -67349.44 & -67194.29 & -67193.46 & -67191.25 & -67187.29 & -48827.46 \\
\hline $\mathrm{N}$ & 315,800 & 315,800 & 315,800 & 315,800 & 315,800 & 226,600 \\
\hline
\end{tabular}


Table A.3: Transition matrix between 2002 and 2007 CMS purchase status for single-unit firms

\begin{tabular}{lcc}
\hline \multirow{2}{*}{2002 CMS Purchases } & \multicolumn{2}{c}{ 2007 CMS Purchases } \\
\cline { 2 - 3 } No & Yes \\
\hline No & 0.80 & 0.58 \\
& 0.20 & 0.42 \\
\hline
\end{tabular}

Notes: Table reports plant shares by CMS purchase status.

Table A.4: IV estimates of the probability of fragmentation and offshoring

Dependent variable is an indicator equal to one if plant $i$ :

\begin{tabular}{|c|c|c|c|c|c|c|}
\hline & \multicolumn{3}{|c|}{ Fragments Production } & \multicolumn{3}{|c|}{ Offshores | Fragmentation } \\
\hline & 1 & 2 & 3 & 4 & 5 & 6 \\
\hline & OLS & IV & IV & OLS & IV & IV \\
\hline Elec. networks $s_{i}$ & $\begin{array}{c}0.094^{* * *} \\
(0.005)\end{array}$ & $\begin{array}{c}0.181^{* * *} \\
(0.022)\end{array}$ & $\begin{array}{c}0.125^{* * *} \\
(0.034)\end{array}$ & $\begin{array}{c}0.022^{* * *} \\
(0.005)\end{array}$ & $\begin{array}{c}0.100^{* * *} \\
(0.021)\end{array}$ & $\begin{array}{c}0.155^{* * *} \\
(0.048)\end{array}$ \\
\hline $\ln \left(\right.$ wage $\left._{h}\right)$ & $\begin{array}{c}0.215^{* * *} \\
(0.031)\end{array}$ & $\begin{array}{c}0.178^{* * *} \\
(0.031)\end{array}$ & $\begin{array}{c}0.126^{* *} \\
(0.050)\end{array}$ & $\begin{array}{c}-0.115^{* * *} \\
(0.031)\end{array}$ & $\begin{array}{c}-0.124^{* * *} \\
(0.031)\end{array}$ & $\begin{array}{c}-0.183^{* * *} \\
(0.058)\end{array}$ \\
\hline $\ln \left(\right.$ VAProd $\left._{i}\right) \mathrm{Q} 2$ & & & $\begin{array}{l}0.075^{*} \\
(0.040)\end{array}$ & & & $\begin{array}{l}-0.038 \\
(0.060)\end{array}$ \\
\hline Q3 & & & $\begin{array}{c}0.062^{* * *} \\
(0.021)\end{array}$ & & & $\begin{array}{c}0.036 \\
(0.031)\end{array}$ \\
\hline MSP 5-20 miles away & $\begin{array}{c}-0.017^{* * *} \\
(0.006)\end{array}$ & $\begin{array}{c}-0.013^{* *} \\
(0.006)\end{array}$ & $\begin{array}{l}-0.010 \\
(0.010)\end{array}$ & $\begin{array}{c}0.015^{* *} \\
(0.008)\end{array}$ & $\begin{array}{c}0.016^{* *} \\
(0.007)\end{array}$ & $\begin{array}{c}0.020 \\
(0.017)\end{array}$ \\
\hline $20+$ miles away & $\begin{array}{c}-0.035^{* *} \\
(0.014)\end{array}$ & $\begin{array}{c}-0.033^{* *} \\
(0.014)\end{array}$ & $\begin{array}{c}0.010 \\
(0.025)\end{array}$ & $\begin{array}{c}0.001 \\
(0.022)\end{array}$ & $\begin{array}{l}-0.003 \\
(0.021)\end{array}$ & $\mathrm{d}$ \\
\hline Port 51-200 miles & $\begin{array}{c}-0.011^{* *} \\
(0.005)\end{array}$ & $\begin{array}{c}-0.014^{* * *} \\
(0.005)\end{array}$ & $\begin{array}{c}0.003 \\
(0.009)\end{array}$ & $\begin{array}{l}-0.008 \\
(0.006)\end{array}$ & $\begin{array}{c}-0.012^{* *} \\
(0.006)\end{array}$ & $\begin{array}{l}-0.013 \\
(0.012)\end{array}$ \\
\hline $200+$ miles away & $\begin{array}{c}0.009 \\
(0.006)\end{array}$ & $\begin{array}{c}0.004 \\
(0.006)\end{array}$ & $\begin{array}{c}0.013 \\
(0.008)\end{array}$ & $\begin{array}{c}-0.018^{* * *} \\
(0.005)\end{array}$ & $\begin{array}{c}-0.024^{* * *} \\
(0.005)\end{array}$ & $\begin{array}{c}-0.025^{* *} \\
(0.010)\end{array}$ \\
\hline $50+$ miles to Mexico & $\begin{array}{l}-0.029^{*} \\
(0.015)\end{array}$ & $\begin{array}{l}-0.028^{*} \\
(0.016)\end{array}$ & $\begin{array}{c}-0.091^{* * *} \\
(0.029)\end{array}$ & $\begin{array}{c}-0.097^{* * *} \\
(0.022)\end{array}$ & $\begin{array}{c}-0.095^{* * *} \\
(0.022)\end{array}$ & $\begin{array}{c}-0.092^{* *} \\
(0.046)\end{array}$ \\
\hline $50+$ miles to Canada & $\begin{array}{l}-0.008 \\
(0.009)\end{array}$ & $\begin{array}{l}-0.008 \\
(0.009)\end{array}$ & $\begin{array}{l}-0.008 \\
(0.015)\end{array}$ & $\begin{array}{l}-0.009 \\
(0.008)\end{array}$ & $\begin{array}{l}-0.010 \\
(0.008)\end{array}$ & $\begin{array}{l}-0.010 \\
(0.015)\end{array}$ \\
\hline NAICS 6 Fixed Effects & yes & yes & yes & yes & yes & yes \\
\hline Adj. $R^{2}$ & 0.09 & 0.08 & 0.07 & 0.10 & 0.08 & 0.02 \\
\hline $\mathrm{N}$ & 71,600 & 71,600 & 22,200 & 21,500 & 21,500 & 5,300 \\
\hline
\end{tabular}

Notes: The left panel corresponds to estimates of the probability that plant purchases CMS. The right panel corresponds to estimates of the probability that a plant purchasing CMS does so from foreign suppliers. IV estimates instrument for electronic network use and productivity using lagged values from 2002. Columns 3 and 6 are based on the subset of single-unit firms that did not purchase CMS in 2002. Standard errors clustered by industry. $*, * *, * * *$ denote $10 \%, 5 \%$ and $1 \%$ significance respectively. $\mathrm{N}$ rounded for disclosure avoidance. $\mathrm{d}$ for disclosure avoidance. 
Table A.5: First stage regressions for the probability of fragmentation and offshoring Each column is the first stage regression for the listed endogenous variable

\begin{tabular}{|c|c|c|c|c|c|c|}
\hline \multicolumn{7}{|c|}{ Probability of Fragmentation Regressions } \\
\hline \multirow{3}{*}{ Instruments } & \multicolumn{3}{|c|}{ Full Sample } & \multicolumn{3}{|c|}{ Adopters } \\
\hline & \multicolumn{2}{|c|}{$\ln \left(V A P_{i}\right.$ Terciles $)$} & \multirow{2}{*}{ Elec.Nets $s_{i}$} & \multicolumn{2}{|c|}{$\ln \left(V A P_{i}\right.$ Terciles $)$} & \multirow[b]{2}{*}{ Elec.Nets $_{i}$} \\
\hline & Q2 & Q3 & & Q2 & Q3 & \\
\hline \multirow[t]{2}{*}{$\ln \left(V A P_{i}\right) \mathrm{Q} 2$} & $0.156^{* * *}$ & $0.089 * * *$ & $0.043^{* * *}$ & $0.163^{* * *}$ & $0.086^{* * *}$ & $0.029 * * *$ \\
\hline & $(0.008)$ & $(0.006)$ & $(0.005)$ & $(0.011)$ & $(0.007)$ & $(0.008)$ \\
\hline \multirow[t]{2}{*}{ Q3 } & $-0.049 * * *$ & $0.392^{* * *}$ & $0.062^{* * *}$ & -0.004 & $0.370^{* * *}$ & $0.036^{* * *}$ \\
\hline & $(0.007)$ & $(0.007)$ & $(0.007)$ & $(0.011)$ & $(0.008)$ & $(0.009)$ \\
\hline \multirow{2}{*}{ Elec netwks $s_{i}$} & -0.007 & $0.038^{* * *}$ & $0.263^{* * *}$ & -0.004 & $0.031^{* * *}$ & $0.328^{* * *}$ \\
\hline & $(0.005)$ & $(0.005)$ & $(0.006)$ & $(0.010)$ & $(0.011)$ & $(0.011)$ \\
\hline Adj. $R^{2}$ & 0.08 & 0.26 & 0.14 & 0.05 & 0.20 & 0.12 \\
\hline F-Test & 462 & 998 & 560 & 166 & 795 & 314 \\
\hline Shea's Partial $\mathrm{R}^{2}$ & 0.03 & 0.12 & 0.04 & 0.03 & 0.13 & 0.04 \\
\hline \multicolumn{7}{|c|}{ Probability of Offshoring Regressions } \\
\hline \multirow[t]{2}{*}{$\ln \left(V A P_{i}\right) \mathrm{Q} 2$} & $0.140^{* * *}$ & $0.097^{* * *}$ & 0.012 & $0.134^{* * *}$ & $0.083^{* * *}$ & 0.002 \\
\hline & $(0.010)$ & $(0.010)$ & $(0.009)$ & $(0.019)$ & $(0.015)$ & $(0.018)$ \\
\hline \multirow[t]{2}{*}{ Q3 } & $-0.080 * * *$ & $0.399 * * *$ & $0.031^{* * *}$ & $-0.034^{* *}$ & $0.359 * * *$ & -0.005 \\
\hline & $(0.010)$ & $(0.010)$ & $(0.010)$ & $(0.017)$ & $(0.017)$ & $(0.018)$ \\
\hline \multirow[t]{2}{*}{ Elec netwks $s_{i}$} & $-0.014^{*}$ & $0.048^{* * *}$ & $0.241^{* * *}$ & -0.015 & 0.014 & $0.284^{* * *}$ \\
\hline & $(0.008)$ & $(0.008)$ & $(0.008)$ & $(0.021)$ & $(0.022)$ & $(0.018)$ \\
\hline Adj. $R^{2}$ & 0.09 & 0.25 & 0.12 & 0.04 & 0.17 & 0.10 \\
\hline F-Test & 234 & 616 & 287 & 39 & 171 & 80 \\
\hline Shea's Partial $\mathrm{R}^{2}$ & 0.03 & 0.11 & 0.04 & 0.03 & 0.10 & 0.04 \\
\hline
\end{tabular}

Notes: Each column reports the coefficients and standard errors for the excluded instruments in the first stage regression of the respective endogenous variable. Instruments are 2002 lagged values. Standard errors clustered by industry. *, **, *** denote $10 \%, 5 \%$ and $1 \%$ significance respectively. F-Test is the F-statistic for a test of the null hypothesis that the instruments are jointly equal to zero. 